\title{
CONSTRUCCIONES MEGALÍTICAS AVANZADAS DE LA CUENCA INTERIOR DEL TAJO: EL NÚCLEO CACEREÑO
}

\author{
ADVANCED MEGALITHIC CONSTRUCTIONS OF THE \\ INNER TAGUS BASIN. THE CÁCERES GROUP
}

\author{
por \\ P. BUENO RAMÍREZ.* \\ R. BARROSO BERMEJO. * \\ R. DE BALBÍN BEHRMANN.*
}

RESUMEN Los autores ponen de manifiesto la riqueza de expresiones megalíticas de todo el actual territorio cacereño atravesado por el Tajo. Defienden la larga secuencia de un megalitismo que con fechas desde el V milenio cal BC. continúa realizándose hasta la Edad del Bronce. Las necrópolis de monumentos de pequeño tamaño, entre las que se detectan auténticas cistas, plantean el uso de estas referencias a la tradición de los ancestros en el marco de las sociedades metalúrgicas del Tajo interior. Con ello asumen que los procesos de individualización no se constatan de modo amplio con el campaniforme, sino que se van instalando paulatinamente en contextos sociales con tendencia a la jerarquización desde el Neolítico Medio, como demuestra el mismo sistema de utilización de los sepulcros colectivos.

\begin{abstract}
The authors, manifiest the wealth of the megalithic expressions of the hole recent land of Caceres, crossed by the Tagus river. They defend the long sequence of the megalithic culture with dates from the V Milenium cal BC. that continues building to the Bronze Age. The Necropolis of monuments of small size, in which are detected authentic stones cist that reflect the use of these references to the ancient tradition in the area of metal groups of the inland Tagus. This asumes that the individuality process are not confirmed deeply with Beaker, but are stablishing slowly into social contexts to trend to hierarchy from Middle Neolithic, as shows the same system of use of colective tombs.
\end{abstract}

Palabras claves Megalitismo. Calcolítico. Bronce. Jerarquización

Key words

Megalithic culture, Copper Age, Bronze Age, Hierarchy.

* Área de Prehistoria. Universidad de Alcalá de Henares. C/Colegios n².28801 ALCALA DE HENARES e.mail:primitiva.bueno@uah.es; rodrigo.balbin@uah.es; rosa.barroso@uah.es

Una versión resumida de este trabajo se presentó como Ponencia a las II Jornadas de Arqueología de Extremadura (Mérida 2000), permaneciendo inédita hasta la actualidad.

ISSN: 1133-4525 ISSN-e: 2255-3924

SPAL 13 (2004): 83-112

http://dx.doi.org/10.12795/spal.2004.i13.03 


\section{INTRODUCCIÓN}

La hipótesis que pretende argumentarse en estas páginas está en relación con la supuesta inexistencia, o parca consistencia, de un calcolítico bien documentado en la zona interior de la cuenca del Tajo, léase de modo más concreto en la actual provincia de Cáceres, y con la falta de evidencias acerca de una secuencia reconstruible para la Prehistoria Reciente del sector. Para plantear esta problemática habremos de hacernos eco de los elementos similares o diferentes de otras zonas interiores de esta misma cuenca, con la ventaja de que nuestro equipo lleva trabajando en ellas desde hace unos cuantos años: nos referimos a las actuales provincias de Toledo, Madrid y Guadalajara.

Dejando de lado las propuestas de un megalitismo retardatario ubicable en la Edad del Bronce (Almagro 1962; Diéguez 1976: 27) y su distribución exclusivamente occidental reveladora de la dependencia del megalitismo portugués -temas que ya hemos criticado en un trabajo reciente (Bueno 2000)-, los monumentos megalíticos extremeños aparecen hoy como el sistema de enterramiento empleado en las cuencas interiores del Tajo y del Guadiana durante el Neolítico, el Calcolítico y el Bronce.

Si para la cuenca extremeña del Tajo no se aceptaba la existencia de neolítico hasta que nosotros argumentamos la presencia de megalitos neolíticos (Bueno 1988) y de cerámicas impresas (Bueno y Piñón 1985), otro tanto se aplicaba para las ocupaciones asociadas a los primeros metalúrgicos. Estas sólo se consideraban para los establecimientos de la cuenca del Guadiana, en la que hallazgos tan espectaculares como La Pijotilla llevaron a volver sobre las hipótesis de fechas tardías para el megalitismo extremeño pues las primeras ocupaciones del territorio se adjudicaban a colonizadores portugueses que habrían traído las técnicas metalúrgicas junto con costumbres de enterramiento megalíticas, entre las que se daban las sepulturas con falsa cúpula y las cámaras con corredor largo (Enríquez y Hurtado 1986; Hurtado 1995). En el panorama que acabamos de describir la entrada del megalitismo portugués se hacía especialmente patente en las zonas fronterizas, ocupando sólo los mejores terrenos, caso aplicable a los conjuntos de Valencia de Alcántara, San Vicente, Barcarrota, etc. Los "eriales" pizarrosos de la mayor parte de la frontera quedarían, pues, deshabitados en razón de la pobreza de sus suelos.

Uno de los parámetros que contribuía a la percepción de la poca entidad de una secuencia neolítico -calcolítico- bronce en la provincia de Cáceres, era la supuesta ausencia de campaniforme. Esta, además se hacía extensiva a otra serie de elementos característicos o asociados a esta cultura como la metalurgia (Hurtado y Huntz 1999: 253). Carencias que se explicaban, en parte, por la idea bastante reiterada de una escasa presencia demográfica que no permitía una sociedad jerarquizada. La cuenca interior del Tajo y, por tanto, Cáceres, Toledo, Madrid y Guadalajara, eran regiones supuestamente pobres, con escaso metal, incluso en el caso de Cáceres sin campaniforme, desde luego sin poblados fortificados y, como decíamos arriba, la evidencia de un despoblamiento notorio que no se soluciona más que con la arribada de nuevos pobladores llegados para unos desde el Sureste (Osuna Ruiz 1975); para otros desde el Oeste (Hurtado 1999), o desde Andalucía.

Las investigaciones de los últimos años, aunque modestas por los presupuestos manejados, han ido dibujando un panorama sumamente alentador que vislumbra un enorme potencial de análisis futuros. Dejando de lado los hallazgos que nos hablan de un Paleolítico Superior equivalente al que se está documentado en otras zonas de la Meseta, las evidencias de un poblamiento neolítico con impresas se abren paso con gran fuerza (Bueno y Piñón 1985; Bueno 1988; Cerrillo et alii 2002; González 1996 y 1999; González y Cerrillo 2000). La constatación de un neolítico bien implantado, visible en la presencia de megalitos de variada tipología, datado en el V milenio cal BC ya fue expuesta (Bueno 1987; 1988; 1991) encontrándose cada vez más argumentos arqueológicos hacia 
el interior de la cuenca, que corroboran estas propuestas (Bueno 1990 y 1991; Bueno et alii 1999a; Bueno et alii 1995 y 2002)

El poblamiento del III y II y milenios también planteaba serias dudas (Pavón Soldevila 1998). No obstante, en los últimos años se han dado a conocer documentos sobre poblados calcolíticos (González et alii 1988 y 1991; González 1993 y 1997), muchos amurallados, y entroncables con el fenómeno general de intensificación de explotación del territorio tan bien documentado en el Guadiana.

En el ámbito de nuestra investigación, los megalitos, la presencia de un núcleo demográfico potente, capaz de dar lugar a conjuntos como el de Valencia de Alcántara o a los compactos conjuntos de la zona Este de la provincia de Cáceres (Bueno 2000; Bueno et alii 2000a) permite abandonar definitivamente las ideas de despoblamiento del sector hasta fechas más recientes de la Prehistoria regional.

En este panorama, el de un análisis cada vez más profundo de las evidencias megalíticas de la región, no es raro que hayamos podido documentar campaniforme y metalurgia y, en definitiva, un decurso largo que plantea la presencia de este sistema funerario, además de en el neolítico, durante el Calcolítico y la Edad del Bronce.

Las cuestiones que someramente describimos son parte de problemática general que afecta al análisis de las secuencias Calcolítico/Bronce en el interior de la Península. Nuestra hipótesis se centra en la visualización de éstas y otras cuestiones a través del registro megalítico y, concretamente, de las necrópolis de monumentos de pequeño tamaño como exponente de una parte de las arquitecturas que definen la transición Neolítico /Calcolítico/Bronce.

Una valoración conjunta de los datos en la cuenca extremeña del Tajo y su comprensión en el panorama global del megalitismo avanzado, especialmente de las evidencias procedentes de los sectores más próximos de Portugal, Salamanca y Toledo, permite enriquecer la perspectiva actual en torno a las costumbres funerarias Calcolíticas y de la Edad del Bronce en la zona que nos ocupa, en tanto que herederas de la ritualidad de las primeras sociedades productoras.

\section{PAISAJES DEL CALCOLÍTICO Y BRONCE EN EL TAJO EXTREMEÑO}

No es fácil proponer una reconstrucción paleoecológica de la zona de la que hablamos a lo largo de la Prehistoria Reciente, pues la escasez de analíticas tanto de flora como de fauna, es muy notoria. Aún así, pueden valorarse una serie de líneas que marcan una tendencia general hacia paisajes abiertos en los que predomina la dehesa como forma básica de cultivo (Bueno et alii 2002).

Las propuestas sobre formas de vida en el sector tienen como base un paisaje humanizado que no puede ignorar la posición fronteriza de éste entre los fenómenos culturales que se adscriben al Sur del Tajo, y los que se relacionan más directamente con el entorno del Duero. En la cuenca interior del Tajo son perceptibles tanto las influencias de los grupos megalíticos alentejanos y algarvios como las de las producciones beiranas, sin olvidar la facilidad de contactos con las culturas del extremo occidental del río, estableciéndose nuestro sector como de un enorme potencial cultural y, una especifidad que los últimos trabajos dejan traslucir.

La posición geográfica a la que nos referimos tiene otra valoración añadida: la de la facilidad de paso que se traduce en la situación de las cañadas y vados tradicionales que hemos valorado en otros trabajos (Bueno 1988; 1991). Estos pasos unen el interior de la Península con el occidente, además de conectar toda la zona con el Norte y el Sur de la Península a través de los caminos de la Cañada Real Leonesa. A ello se suman las facilidades de paso a través del Sistema Central entre la Extremadura española, la Beira y Tras - os- Montes (Sanches 2000: 196), por lo que nuestra insistencia en

ISSN: 1133-4525 ISSN-e: 2255-3924

SPAL 13 (2004)

http://dx.doi.org/10.12795/spal.2004.113.03 
la situación geográfica quiere destacar su valor estratégico para el control y conocimiento tanto de objetos como de ideas.

Las llanuras acompañadas de pequeños montes-islas en los que sobresale el granito son el espacio predominante en el sector portugués (Vilaça 2000: 163) y lo mismo puede decirse del territorio cacereño o toledano pues no es hasta las zonas más interiores donde el Tajo discurre por sectores realmente montañosos.

Uno de los recursos que más destacan en todo el recorrido del río es el metal, especialmente el cobre del que tenemos muchas evidencias en la zona portuguesa (Vilaça 2000: 163) y en la española (Barroso et alii 2003;Florido Laraña 1987; Mapa Metalogenético de España), sin dejar de lado la explotación de los auríferos fluviales (Bueno et alii 2000b). No hay que olvidar que la zona granítica centro ibérica contiene importantes mineralizaciones entre las que destaca el cobre (Dallmeyer y García 1990: 212), respondiendo la provincia de Cáceres, de la que ahora nos ocupamos, a ese esquema geológico.

De las numerosas localizaciones de calcopiritas de la provincia (Bueno et alii 2000a) podemos destacar Piedras Albas, Alcántara y Valencia de Alcántara por tratarse de importantes núcleos megalíticos en los que están presentes los monumentos de pequeño tamaño, igual que ocurre en el núcleo noroeste con los conjunto de Las Hurdes asociados a poblados con secuencia Calcolítico/ Bronce (Bueno y González 1995; y com. personal M. A. López), y en el amplio núcleo oriental en este caso de fácil acceso a las mineralizaciones próximas de Toledo y Madrid. (Figura 1).

Las posibilidades de explotación metalúrgica concurren con una significativa presencia de estaño y vienen a incidir en la cuestión de la supuesta pobreza de recursos de los terrenos de sustrato esquistoso, pues es precisamente en éstos donde los indicios mineralógicos son más notorios. Efectivamente, al igual que en otras regiones esquistosas del Suroeste (Parreira y Serpa 1995: 246), los grupos aquí asentados practican una economía mixta, agrícola y ganadera, a la que acompaña el laboreo de metales.

En las valoraciones sobre las potencialidades del sector ha pesado mucho la idea de que sólo los sectores graníticos disponían de buenas tierras para el cultivo, mientras que las áreas de sustrato pizarroso, normalmente con suelos algo más pobres no podían sostener modos de vida agro-pastoriles de un cierto desarrollo (Oliveira 2000a).

La pobreza a la que nos referimos se propone en dos versiones: bien se entiende que los monumentos pequeños son globalmente los más antiguos de la secuencia megalítica y, por tanto, fueron realizados por grupos que aún no manejaban las tecnologías de la agricultura y la domesticación (Santos 2000: 421), bien se propugna una contemporaneidad genérica de estas formas más modestas con los dólmenes de gran tamaño, desarrollándose las primeras en un ambiente de marginalidad que supone la práctica de una ganadería con animales de escaso rendimiento como las cabras y la inexistencia o nula representatividad de la agricultura (Oliveira 2000a: 432).

Como ya hemos señalado en trabajos recientes (Bueno 2000; Bueno et alii 2000b), los análisis polínicos procedentes de Valle Pepino I, una cista, en la necrópolis de monumentos de pequeño tamaño de Santiago de Alcántara y los de Huerta de las Monjas, un dolmen de granito con cámara y corredor en Valencia de Alcántara, no son muy diferentes. Ambos indican un paisaje abierto con encinares acompañados de herbáceas relacionadas con la actividad antrópica que P. López (1994: 98-99) explica por la presencia de pastos, tanto en Valencia de Alcántara (sustrato granítico), como en Santiago de Alcántara (sustrato pizarroso), además de por la verificación de trigo que queda confirmada en los propios depósitos funerarios pues una vasija de Trincones 1, dolmen de Alcántara, muestra granos del cereal en la pasta.En todo caso,la presión antrópica sobre el medio es evidente,no sólo en las muestras mencionadas sino en recientes análisis antracológicos efectuados en el dolmen de Joaniña en Cedillo (Duque Espino 2005). 


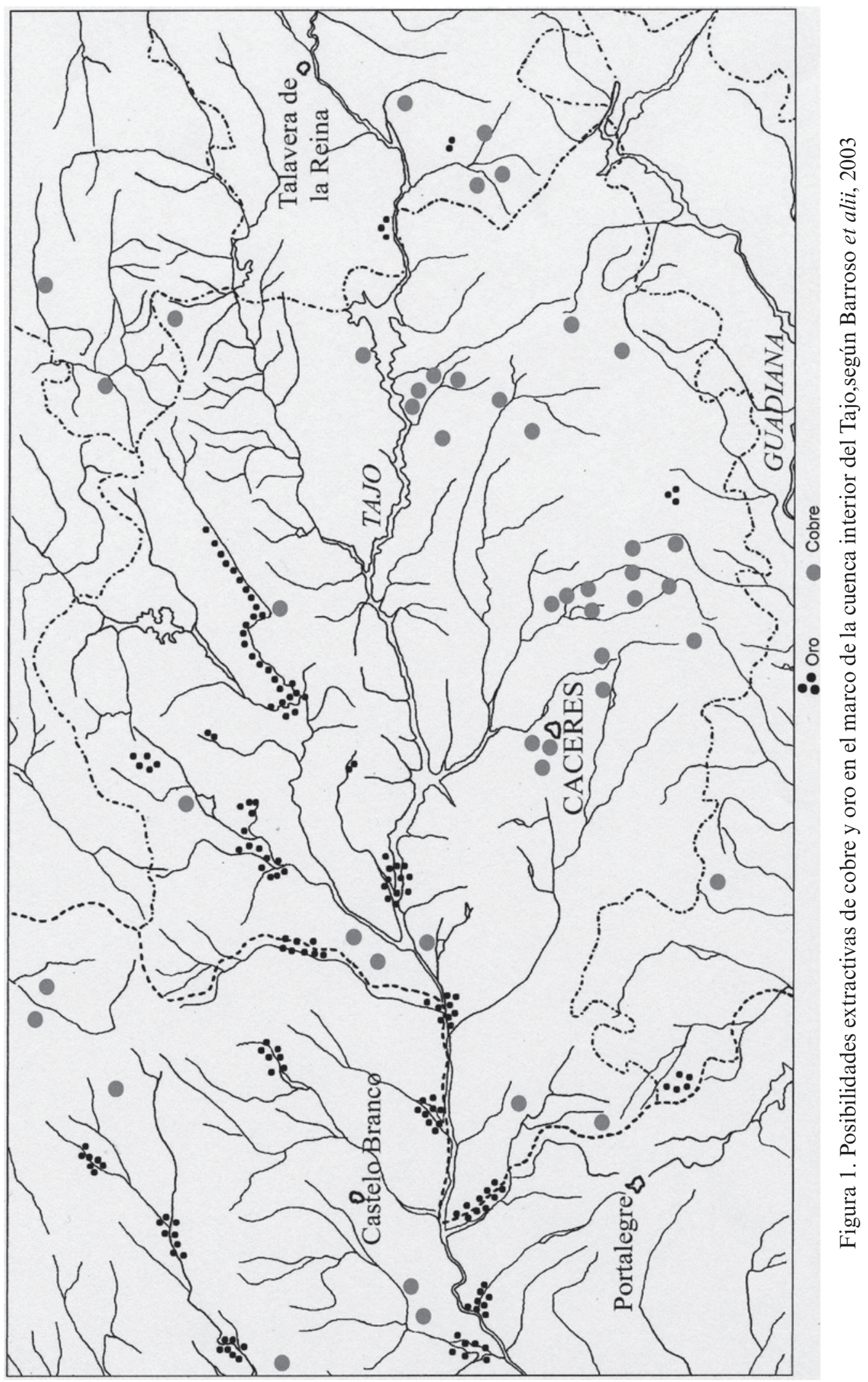

ISSN: 1133-4525 ISSN-e: 2255-3924

SPAL 13 (2004) 
Los indicadores de humedad son mayores que los actuales destacando la presencia de alisos y avellanos en la muestra de Santiago de Alcántara, lo que coincide con el análisis de Guillén Oterino (1982) centrado en la demostración de la presencia de castaño en estos contextos de dehesa más húmeda, al estilo de la que aún hoy puede observarse en zonas extremeñas como la presierra del Pino en Valencia de Alcántara.

De hecho, estudios especializados definen el área de Alcántara de cultivo cerealístico, especialmente avena (Mapa de cultivos y aprovechamientos de la provincia de Cáceres), lo que encaja con los análisis de suelos que describen los terrenos de Piedras Albas y Zarza la Mayor hasta el Salor pasando por Garrovillas, por tanto incluyendo Alcántara y Santiago de Alcántara como enclaves con rocas básicas menos resistentes que permiten la formación de suelos arcillosos biológicamente activos (Redondo y Del Río 1977: 189).

Desde una perspectiva amplia, la única que por el momento nos permiten los datos que valoramos, la dedicación mixta agrícola/ganadera es la más factible tanto en los sustratos graníticos como en los terrenos de sustrato pizarroso sobre todo de tener en cuenta que nos referimos a una agricultura técnicamente poco sofisticada. Ciertamente que los terrenos de sustrato granítico podrían ofrecer una mejor productividad agrícola si los comparamos con los pizarrosos de la "Raya", pero no si los comparamos con los terrenos aluviales del Guadiana en los que también se documentan monumentos megalíticos de variada tipología.

Recordaremos aquí que la dehesa no es una forma natural del paisaje, sino el producto de una intervención humana continuada (Balcells 1979) y, en este sentido, un cultivo. Los datos recientemente obtenidos de la ocupación habitacional documentada bajo el túmulo del dolmen de Azután (Toledo), confirman la intervención antrópica en el "cultivo" de la dehesa y el cultivo de cereales en los claros del encinar próximos al monumento, ya en el V milenio cal BC. (Bueno et alii 2002; Bueno et alii 2005)

Respecto a la incidencia o no de las técnicas de cultivo, no deja de ser interesante la evidencia de molinos y molederas en el entorno de los monumentos, en el entramado tumular o, incluso, al interior del sepulcro. Este hecho ha sido destacado en más de una ocasión (Bueno 1988: 173-174; Bueno,1991:103) y ,siendo contrastado en los monumentos de tamaño importante, también lo es en los pequeños.

Otro tanto cabe decir de los útiles de piedra pulida como hachas y azuelas relacionables con trabajo de la tierra que supuestamente no se localizaban o eran muy escasos en monumentos de pequeño tamaño (Oliveira 2000a: 433). De ellos tenemos ahora buenos ejemplos.

Así en momentos contemporáneos al uso de las necrópolis de monumentos de pequeño tamaño podemos proponer sistemas de explotación del territorio de carácter mixto con especial incidencia en el cultivo de la dehesa como medio de proveerse de pastos y de bellotas junto a sembrados de cereal en sus claros o, en los sectores de valle próximos a los ríos. Y sin duda este paisaje con explotaciones agro-pecuarias y posibilidades metalíferas es más común en la cuenca interior del Tajo de lo que hasta hace pocos años se planteaba.

\section{USO Y CONSTRUCCIONES DE MEGALITOS EN EL TAJO EXTREMEÑO DESDE FINES DEL IV MILENIO CAL BC.}

La primera consideración a establecer para valorar la construcción de monumentos en el área que nos ocupa, es la de la continuidad que impera en la ritualidad funeraria megalítica. Nos referimos a la fuerte continuidad ideológica que puede deducirse de un uso similar del espacio funerario, entendiendo que éste es un espacio ritualizado. Los gestos que se realizan en él no son aleatorios 
sino que responden a parámetros normativizados, idea que se ve reforzada por la presencia de una simbología explícita, el Arte Megalítico, que reitera temas, asociaciones y ubicaciones. Los objetos que acompañan a los difuntos son básicamente los mismos: ápices de flecha, adornos, contenedores cerámicos y útiles pulimentados, si bien pueden apreciarse diferencias en las materias primas, a veces de origen exótico, además de en la tipología de las piezas.

Al igual que los símbolos que "decoran" el espacio funerario, los objetos tienen un papel en los gestos funerarios conocido por todos los que practican este sistema de enterramiento y utilizado durante casi tres mil años. Sin dejar de lado que nuestro concepto del tiempo está muy alejado del de nuestros antepasados para los que la vinculación con los ancestros entra dentro de la tradición (Bradley 1991: 210) y, en ese sentido, no refleja la escala temporal de los actos cotidianos (Parreira y Serpa 1995: 242).

Dada la relativa escasez de fechas C14 para el megalitismo cacereño, un esquema de su desarrollo ha de recurrir a la "cronología gruesa" asentada en la tipología de los materiales .Dicha cronología "gruesa" se argumenta en relación con la presencia o ausencia de microlitos, los tipos de las puntas de flecha, la detección de piezas cerámicas carenadas o de platos con borde almendrado, la cerámica campaniforme y, desde luego el metal.

La mejor referencia para valorar la incidencia de las variables arquitectónicas en la cuenca media del Tajo es, sin duda, el conjunto megalítico de Valencia de Alcántara. Nuestro análisis de sus necrópolis (Bueno 1987 y 1988) sirvió en su día para proponer un uso diacrónico de las grandes arquitecturas características de la región en momentos paralelos a las áreas clásicas portuguesas. Así se hablaba por primera vez de ocupaciones neolíticas y de una variedad arquitectónica hasta el momento no documentada, entre la que destacaban pequeñas arquitecturas asociadas en necrópolis amplias, cuyos materiales, aunque escasos, apuntaban a fechas avanzadas.

Los datos obtenidos fueron la base para propuestas más amplias como hipótesis de interpretación para el megalitismo extremeño (Bueno 2000). Diferenciamos un primer grupo de arquitecturas, las cámaras con corredor largo de buen tamaño utilizadas a lo largo de un periodo importante de tiempo, pues, arrancando probablemente de un neolítico datable en el V milenio cal BC continuaron en uso durante el Calcolítico y el Bronce, como muestra la presencia de puntas Palmela y campaniforme en el dolmen de Lácara, además de las secuencias conocidas en otras arquitecturas del mismo área (Bueno 1988; Oliveira 1997b; Vilaça 1995).

Otro grupo de arquitecturas, las cámaras con corredor corto, no eran conocidas en la región. Durante nuestro estudio de Valencia de Alcántara no disponíamos de evidencias sobre una cronología larga para su uso, pero hoy, sí. Por un lado, de las obtenidas en los recientes trabajos de excavación del conjunto de Reguengos de Monsaraz (Gonçalves y Sousa 2000; Gomes 1997) y, por otro de nuestras excavaciones en las necrópolis alcantarinas (Bueno et alii 1998a:174). Por tanto, las cámaras de corredor corto son otro tipo de arquitectura que puede continuar utilizándose en el Calcolítico, pese a su origen más antiguo.

La presencia de los platos de borde reforzado en el área de la que nos ocupamos, tampoco era muy abundante pero nuestras excavaciones en Valencia de Alcántara (Bueno y Balbín 1991: 101), Alcántara y, recientemente en Santiago de Alcántara, han venido a ofrecer interesantes evidencias que hoy podemos sumar a las documentadas tanto al occidente como en los sectores más interiores de la cuenca (Bueno et alii 1999b: 100).

Una buena referencia en la zona para esta tipología de platos es la que ofrecen los poblados de Charneca do Fratel, en Vila Velha de Rodao, muy próximo a Alcántara y a Santiago de Alcántara, y el de Monte do Trigo, en el mismo sector portugués. El primero está asociado a las mámoas de Charneca das Canas (Silva 1991) y el segundo dispone de dos fechas C14: $4610 \pm 170$ BP y 4300£180 BP (Oliveira 1998: 245), que sitúan estas producciones a fines del IV milenio cal BC .

ISSN: 1133-4525 ISSN-e: 2255-3924 
El otro grupo de arquitecturas presente en el conjunto de Valencia de Alcántara era el de los monumentos de pequeño tamaño, con materiales calcolíticos en sepulcros como Porqueros III (Bueno 1988: 30). Estas necrópolis se sumaban a las de Santiago de Alcántara y a formas similares, dibujando un panorama nuevo en la consideración de estas arquitecturas, no sólo en la Extremadura española sino en todo el megalitismo del suroeste (Bueno 1989,1994 y 2000).

En el contexto de estas pequeñas arquitecturas hemos de tratar la cuestión de las cistas adscritas de modo casi automático a la Edad del Bronce por su paralelismo con elementos portugueses clasificados en su día por Schubart (1975). Ya Gil -Mascarell et alii (1986: 41) reparan en la dificultad de separar los ajuares de éstas de los calcolíticos. Los datos que nosotros publicamos de la necrópolis de Santiago de Alcántara, especialmente los referidos a Valle Pepino I, monumento que tanto desde el punto de vista constructivo como desde el aspecto de las ofrendas e, incluso, de la situación de las mismas, puede considerarse una cista, constituyen una aportación valorable en el sentido de asociar cistas a monumentos de pequeño tamaño en una dinámica constada en zonas portuguesas. Así la necrópolis de Fonte de Malga (Kalb 1987) o la recientemente documentada de Tabuaço, al norte de Portugal (Perpetuo et alii 1999). Más próxima, la necrópolis de las Arquetas verifica la misma asociación (Enríquez y Carrasco,1995).

Las reminiscencias constructivas y materiales se suman a la relativamente común presencia de más de un enterramiento (Pavón 1998b: 189), redundando en la fuerza de un ritual megalítico que, en ocasiones, se acompaña de elementos antropomorfos que reiteran esa tradición.

Esta cuestión nos remite a la problemática ya expresada por distintos autores de la poca consistencia del término Bronce del Suroeste en relación a lo que hoy conocemos sobre las expresiones de los primeros momentos del Bronce en la zona que nos ocupa. El peso de la tradición megalítica y la adaptación a los distintos paisajes de esta vasta región parecen haber favorecido respuestas culturales relativamente diferenciadas que explican la contemporaneidad de las necrópolis de cistas con el uso de algunas estructuras de pequeño tamaño, el enterramiento en sepulturas de falsa cúpula, en estructuras circulares excavadas en el subsuelo (Hurtado 2000) o en cámaras con corredor ortostático.

Las cistas se imbrican en el espectro de los monumentos de pequeño tamaño de tradición megalítica y su genérica fecha de realización en la Edad del bronce habría de extenderse hacia atrás, dibujando una evidencia más de la continuidad de las expresiones funerarias Calcolítico / Bronce que también indican el resto de los contenedores de los que en este trabajo nos ocupamos. Como muestra, la fecha del último nivel de depósitos en la sepultura de falsa cúpula de Huerta Montero: $3700 \pm 100$ BP (Blasco y Ortiz 1991).

La asociación de muchas de estas cistas a poblados "calcolíticos" (Hurtado 2000: 388) constituye un argumento más a sumar a esta propuesta de su cronología larga.

Excavaciones recientes han constatado la continuidad manifiesta en el registro arqueológico entre las fases plenamente calcolíticas y las de la Edad del Bronce. Nos referimos concretamente a los datos del poblado de Palacio Quemado en Badajoz, asociado a una necrópolis de cistas (Gil- Mascarell et alii 1986) y con una fecha C14 de su ocupación más reciente -1620 a.C.- con platos o vasos con carena que en nada desentonan de los elementos documentados en la primera fase de la ocupación (Hurtado y Enríquez 1991). La primera fase del yacimiento de la Solana de Alange incide en la misma cuestión: la presencia de formas vinculadas al Calcolítico en estratos claramente posteriores a éste. El autor lo solventa proponiendo denominarla "epicalcolítico" (Pavón 1998: 80).

La mayor diferencia entre unos sepulcros y otros se ha establecido sobre todo por el uso individual o colectivo de los mismos. La constatación de enterramientos individuales en silos (Hurtado 2000: 383) en el mismo poblado de la Pijotilla, lugar del que conocemos una necrópolis con sepulcros 
colectivos, da una idea de la variabilidad que podemos detectar sin que sea posible destacar un modo u otro como el más representativo hasta bien avanzada la Edad del Bronce, al igual que sucede más al interior (Bueno et alii 2000a; Fabián 1995).

Las sepulturas de falsa cúpula constituían el único tipo reconocido de antiguo en el megalitismo extremeño, junto con las cámaras de corredor largo. Si nos atenemos a las fechas conocidas (Soares y Cabral 1993), también éstas son arquitecturas de largo recorrido, entendiendo con ello que comienzan a construirse en el Neolítico avanzado, continúan utilizándose a lo largo del Calcolítico e, incluso del Bronce como proponen los datos ya conocidos de Olivenza (Schubart 1973). Desgraciadamente no disponemos de una buena información para este tipo de sepulturas en el área extremeña del Tajo, aunque el trabajo que hemos presentado sobre el poblado y necrópolis del Canchal (Bueno et alii 2000) ofrece argumentos para situar su implantación a partir del Neolítico final del sector.

Los materiales asociados abogan por un uso dilatado que abarcaría el Calcolítico y el Bronce. Algunos dejan traslucir la fuerte relación con el extremo occidental del Tajo. Así el pectoral realizado en piedra verde de una de las sepulturas de Garrovillas que reproduce un objeto idéntico al del tholos de Pai Mogo, en Lourinha, aquí realizado en caliza.

Los datos del Guadiana (Blasco y Ortíz 1991) proponen su asentamiento ya en la primera fase del calcolítico, en consonancia con las fechas manejadas para esta época en yacimientos emblemáticos portugueses (Soares y Cabral 1987), por lo que no es fácil argumentar fuertes décalages cronológicos entre los supuestos colonizadores calcolíticos (Hurtado 1995: 57) y los colonizados. La misma situación de los sepulcros de falsa cúpula en el área extremeña del Tajo, que se aleja de lo exclusivamente occidental como propone este argumento, aboga una vez más por la elaboración de hipótesis algo más complejas (Bueno 2000).

Las fechas de Huerta Montero sirven para valorar la secuencia extremeña como perfectamente al hilo de lo que sucede en todo el área occidental, además de ofrecer un termino ante quem para materiales como los ídolos tipo Almizaraque, la presencia de algunos útiles óseos etc. que, por el momento no se han localizado en cámaras con corredor largo del Tajo extremeño. Las mencionadas figurillas antropomorfas plantean otra cuestión, que retomaremos más tarde, cual es la de la circulación de ideas y, probablemente productos, entre el Este y el Oeste, a través de los grandes valles entre los que el Guadalquivir debió jugar un papel de peso (Nocete 2001).

Desde el punto de vista constructivo, algunas de las cámaras con falsa cúpula de la cuenca del Guadiana plantean una relación expresa con las cuevas artificiales que se visualiza en la excavación de parte de las construcciones, al estilo de algunas de las necrópolis de La Pijotilla y de las de Guadajira (Hurtado 1999), como sucede en las áreas clásicas portuguesas.

La documentación de cuevas artificiales en la provincia de Toledo (Bueno et alii 1999a y 2000), propone la posible existencia de éstas en la Extremadura española y sólo el tiempo y la investigación nos dirán si nuestra profecía tenía base empírica. Con la evidencia de la necrópolis toledana de Valle de las Higueras, la posible necrópolis también con cuevas artificiales de Yuncos y la reinterpretación que proponemos de la necrópolis Ciempozuelos (Madrid) como una agrupación de cuevas artificiales, las referencias de Miajadas resultan más creíbles (Roso de Luna 1901), si bien su localización actual ha sido de todo punto imposible.

Cámaras de corredor largo y de corredor corto de buen tamaño realizadas en granito o en pizarra, se usaron como contenedor funerario desde el Neolítico hasta el Calcolítico. Los sepulcros de falsa cúpula se unen a los contenedores utilizados con seguridad en una primera fase del calcolítico aunque es más que probable que ya se estén usando en los momentos finales del Neolítico, al igual que podemos proponer para los contenedores de pequeño tamaño que, con sus diversas plantas, reflejan por encima de todo un intento expreso de emulación de las grandes arquitecturas.

ISSN: 1133-4525 ISSN-e: 2255-3924 
Otros contenedores sepulcrales como las cuevas naturales no son descartables. Enterramientos en cueva están documentados en la bibliografía. Sus datos dispersos son poco indicativos, si bien parecen plantear un panorama semejante al del uso de cuevas naturales en el litoral portugués con materiales y rituales idénticos a los megalíticos.

\section{ARQUITECTURAS DE PEQUEÑO TAMAÑO EN EL AREA EXTREMEÑA DEL TAJO}

De la situación que describíamos en los trabajos de los años 80 y 90 (Bueno 1987; 1989 y 1994) a la perspectiva que hoy podemos ofrecer acerca de las necrópolis con monumentos de pequeño tamaño en el área que nos ocupa, nuestros conocimientos han avanzado sensiblemente, contribuyendo a diseñar una interpretación más compleja de lo que se venía proponiendo. (Figura 2)

Por un lado destaca su imbricación en un territorio codificado (Bueno y de Balbín 2000 a y b) en el que las distintas grafías: pinturas y grabados, manifiestan una compartimentación simbólica del espacio. La presencia de estas grafías al interior de los monumentos de pequeño tamaño (Bueno et alii 2000 a y b; Bueno y de Balbín 2000c) es, igualmente, una novedad de trascendencia cultural que conecta con las referencias que ya habíamos argumentado acerca de la asociación de las estelas antropomorfas con las cámaras de un único espacio y escasa altura (Bueno y González 1995), además de con sepulturas de falsa cúpula (Bueno y Balbín 1997a).

Por otro, la extensión de estas necrópolis hacia el Tajo interior es un hecho. Su documentación en el área de la Vera (Bueno et alii 2000a) y en la provincia de Toledo (Carrobles et alii 1994; Bueno et alii 1999b: 17), augura nuevas perspectivas en el sector, además de incidir en la distribución no exclusivamente occidental del megalitismo extremeño (Bueno 2000: 72). En Cáceres ocupan prácticamente toda la provincia y seguro que los datos se acrecentarán deprisa en relación con los proyectos en fase de realización.

Las comarcas de las Hurdes y Sierra de Gata están muy bien conectadas con los accesos a la región del Duero y esta facilidad se concreta en similitudes culturales y ergológicas como las mencionadas estelas antropomorfas, que además de estar presentes en Extremadura, aparecen en Salamanca (Bueno 1990; 1991 y 1995) y Portugal (Bueno y Balbín 1998; Sousa y Rebanda 1993; Sousa 1996).

Mélida da noticia de dos cinceles y un fragmento de hacha procedentes de la Sierra de Gata como indicadores de una población megalítica de la que el dolmen de Valverde del Fresno era un ejemplo, hoy desaparecido (Mélida 1924: 10; Leisner 1959: 328 y Taf.55,8; 1960: 21). Materiales megalíticos en Villamiel y Villasbuenas (García 1985), además de hachas pulimentadas y puntas de flecha se detectan en San Martín de Trevejo (Soria 1979: 903) en el mismo lugar que ya señaló Maluquer (1956: 18) como paralelo al hábitat de la Mariselva, en Salamanca. La proximidad a Salamanca posee el interés de la documentación de necrópolis que incluyen monumentos de pequeño tamaño. Nos referimos a la agrupación funeraria de Piedras Hincadas, en el Valle, término de Ciudad Rodrigo (Leisner y Schubart 1964) con dos cistas y un dolmen. De uno de los monumentos pequeños, Morán recogió dos pulimentados a los que se añade otro recogido recientemente junto con una punta de aletas y un microlito (Delibes y Santonja 1986: 56) y la localización de nuevas evidencias del mismo (López et alii 2000: 271). La necrópolis de la Rábida, cercana en disposición arquitectónica a conjuntos como el hurdano del Madroñal (Bueno y González 1995: fig. 6), reitera asociaciones semejantes en la zona portuguesa, como la ya mencionada necrópolis de Fonte de Malga (Kalb 1987) o las que se están estudiando en la cuenca del Mondego (Valera 2000: 154).

Las necrópolis con monumentos de pequeño tamaño de las Hurdes, también poco estudiadas, se relacionan igualmente con las salmantinas y las portuguesas. Las arquitecturas documentadas 


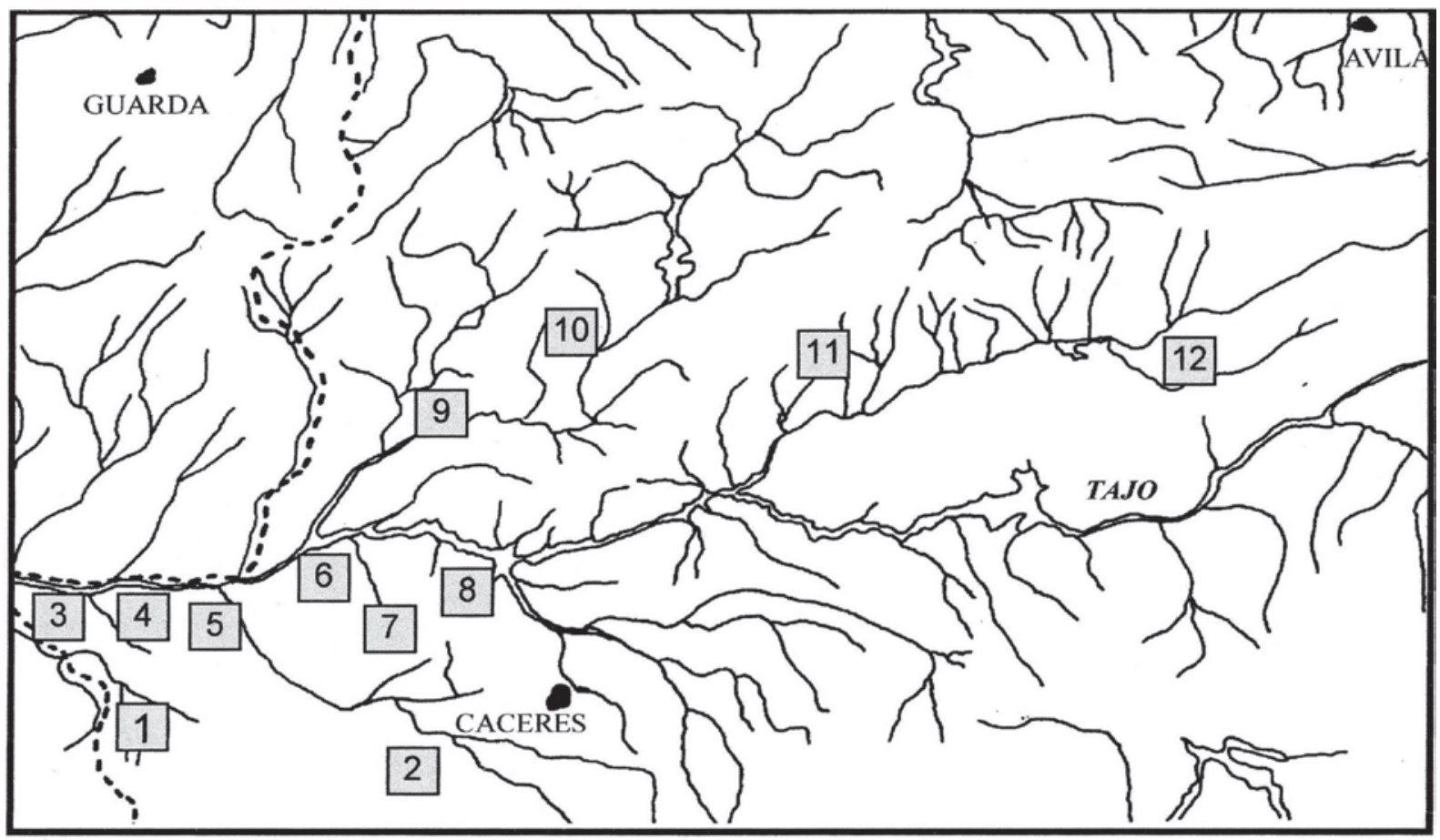

$50 \mathrm{Km}$.

Necrópolis con cámarasa de pequeño tamaño: 1. Valencia de Alcántara; 2. San Pedro; 3. Cedillo; 4. Herrera de Alcántara; 5. Santiago de Alcántara; 6. Alcántara; 7. Brozas; 8. Garrovillas; 9. Hurdes-Gata; 10. Montehermoso; 11. Jaraiz de la Vera; 12. La Cumbre.

Figura 2. Distribución geográfica de las necrópolis con monumentos de pequeño tamaño documentadas hasta la actualidad en Cáceres y Toledo.

son cámaras simples cerradas excavadas en el terreno, de forma que responden al concepto de cistas. Añaden, además, su asociación con estelas antropomorfas (Bueno 1987; 1990; 1991 y 1995).

La asociación de las estelas antropomorfas con arquitecturas megalíticas se confirma en la Extremadura española en la sepultura de Toniñuelo (Leisner 1935; Bueno y Balbín 1997a y 2000c), en las cistas de la Vihuela (Bueno y Balbín 1991b) y en las pequeñas sepulturas de Las Hurdes (Bueno y González 1995), con el interés en este último caso de que las necrópolis pequeño tamaño en las que se ubican se encuentran en el entorno de poblados con materiales calcolíticos. Este es el caso de los poblados y necrópolis del Madroñal, La Coronita o el Collao (Bueno y González 1995: 104). De este último lugar, el Collao proceden las dos piezas del Cerezal (Bueno 1987; Sevillano 1982).

Es más que posible que estos poblados continúen su secuencia durante el Bronce y que las arquitecturas funerarias que se les asocian reflejen un fenómeno similar.

Otras evidencias en las Hurdes proceden de los trabajos realizados en los 70. Almagro Gorbea y Hernández excavaron los sepulcros del Chanquero y el Matón, en Hernán Pérez. El primero de ellos, una cámara con corredor largo y poca altura en pizarra y, el segundo, una sepultura de falsa cúpula. Recientemente, González (1993) ha localizado un poblado calcolítico/bronce en sus inmediaciones. La presencia de placas de arenisca (Almagro y Fernández 1977) como las de Trincones I, en Alcántara (Bueno et alii 1999c) constituye una evidencia más de la cercanía cronológica y cultural de estas expresiones. 
Una asociación arquitectónica a añadir es la que documentamos a raíz de las prospecciones desarrolladas en torno a la tesis doctoral de uno de nosotros (Bueno 1987: 111-112; 2000: 49) que nos permitió localizar la necrópolis de la Dehesa de Arriba, en el Prado Castaño junto al río Arrago. En ella, cámaras de corredor largo de tamaño normal se asocian a cámaras simples abiertas de poca altura.

Al Este, agrupaciones organizadas como la recientemente descrita junto al poblado del Canchal, en Jaraíz de la Vera (Bueno et alii 2000a) confirman la relación de los monumentos de pequeño tamaño con ocupaciones habitacionales datables desde el Neolítico Final hasta el Bronce y su coexistencia con las arquitecturas de falsa cúpula. Destaca la presencia, en ese conjunto, de cobre en la cámara con corredor $\mathrm{n}^{\circ} 12$ y de variscita en el sepulcro 1, además de productos cerámicos semejantes a los localizados en el Calcolítico del Guadiana (Bueno et alii 2000a). Más al interior, la necrópolis de la Cumbre (Carrobles et alii 1994), en Toledo, certifica la presencia de estas arquitecturas de pequeño tamaño que, seguro poseerán más evidencia en el sector.

Al Sur del Tajo, las comarcas occidentales forman un "continuum" con la Penillanura cacereña cuya riqueza es bien conocida. Ya hemos hecho referencia a las necrópolis de este tipo en término de Valencia de Alcántara. Las cámaras simples rectangulares abiertas de Porqueros 3, 4 y 5 se asocian a las cámaras con corredor largo de poca altura de Porqueros 1 y 2. Los ejemplares de Terrías, Palomares o Chaves, abundan en la variedad de estas arquitecturas al igual que los materiales recogidos (Bueno 1988: 25-33) apuntan a una cronología Neolítico Final /Calcolítico.

La continuidad de estas necrópolis hacia Santiago de Alcántara, Cedillo, Herrera y Alcántara es un hecho, del mismo modo que sus evidencias hacia el interior: Garrovillas o Sierra de San Pedro, su relación con los conjuntos desarrollados hacia el Sur: Alburquerque, Villar del Rey etc. (Bueno 2000: 55) y, desde luego la conexión con los conjuntos portugueses (Bueno 1994: 75-87).

Nuestras excavaciones en Santiago inciden en la asociación arquitectónica de cámaras simples rectangulares abiertas y cámaras con corredor largo, a las que se suman cámaras simples rectangulares cerradas, cistas y cámaras simples circulares. La confluencia en la misma necrópolis de monumentos de mayor altura y de menor altura, también se ha visto recientemente confirmada. Los materiales: hachas pulimentadas, hojas de sílex y cerámica, reflejan elementos semejantes a los localizados en los megalitos tradicionales relativizando argumentos negativos (Oliveira 2000), acerca del contenido de estas pequeñas sepulturas.

Los trabajos desarrollados recientemente por nuestro equipo han permitido documentar un área de depósitos exterior a la entrada del monumento de Lagunita III, una cámara con corredor en esquisto de buen tamaño, idéntica a las documentadas delante de algunos monumentos de falsa cúpula de la necrópolis de Los Millares. Cazuelas de carena baja, platos de borde almendrado, puntas con aletas y estatuas antropomorfas definen una serie de gestos rituales de enorme interés de cara a las tradicionales interpretaciones de marginalidad cultural del sector.

En el término de Herrera se habían recogido pequeñas sepulturas (Bueno 1988 y 1994: 42-43), caso de la cámara simple circular de Solana, muy próxima al monumento de corredor largo de Bordalo (Bueno 1988), pero no es hasta los trabajos de Oliveira cuando podemos disponer de alguna información más concreta. Así una cámara con corredor muy desarrollado en el Cerro de la Caldera semejante a la de Lagunita III o Gorrón Blanco en Santiago o la muy interesante descripción de la necrópolis de Sesmo que incluye cistas delimitadas por círculos como las más clásicas del bronce del Suroeste junto con una sepultura megalítica (Oliveira 1997: 23-24), planteando asociaciones funerarias al estilo de la ya comentada de Fonte de Malga (Kalb 1987: 102).

Las necrópolis de Cedillo poseen la ventaja de que al igual que las de Santiago y las de Alcántara han sido objeto de trabajos arqueológicos recientes. La reiteración de las asociaciones arquitectónicas que venimos señalando, la confluencia de agrupaciones numéricamente importantes y la 
documentación de piezas de ajuar que incluyen buen número de pulimentados, hojas de sílex y algo de cerámica comienzan a asentar una propuesta de adjudicación cultural que las fechas recientemente conocidas (Oliveira 1998: 214) afianzan. La amabilidad del Dr. Oliveira nos ha permitido conocer las plantas y los ajuares de las últimas excavaciones en Cedillo que reflejan la presencia en estos conjuntos de cámaras rectangulares abiertas muy alargadas con piezas transversales intermedias al estilo de las formas desarrolladas de Monchique que cuentan con metal y brazales de arquero en los ajuares (Formosinho et alii 1953).

Las fechas a las que hacemos referencia proceden del sepulcro de Joaniña, una cámara rectangular con corredor compartimentado y suelo enlosado. La más antigua, $5400 \pm 210 \mathrm{BP}$, procede de un sector ceniciento localizado bajo el enlosado de la cámara, por tanto anterior a la construcción y sin ningún material arqueológico asociado. La más reciente, $3840 \pm 170 \mathrm{BP}$, está tomada del conjunto de carbones identificados al interior del monumento, en la zona de contacto entre la cámara y el corredor, sector del que proceden la mayor parte de los objetos del ajuar documentados (Oliveira 1998: 214).

Recientemente hemos obtenido una fecha $\mathrm{C} 14$ del suelo de la cámara del dolmen de Trincones I, en Alcántara: 3600£60BP (Beta 197160 ), que coincide con la de Joaniña y se asocia cerámica campaniforme incisa.

Nuestro intento de datar carbones del sepulcro de Baldío Gitano (Bueno 1994), fue infructuoso, pero nos parece interesante constatar la similitud de la posición de éstos y de los de Joaniña, que concuerda con la presencia de piezas pétreas de pequeño tamaño delimitando la entrada de la cámara y la del corredor. En otros lugares argumentamos la conexión simbólica de estas piezas con las representaciones antropomorfas (Bueno y Balbín 1994; 1996 y 2000c) constatadas en el próximo conjunto alcantarino (Bueno et alii 1999c y 2000b).

En este ámbito de la relación de piezas exentas con contenidos simbólicos de carácter antropomorfo, se incluye el dolmen de la Miera en Valencia de Alcántara (Enríquez y Carrasco 2000: 274) con piezas de poca altura en forma de tronco de cono, muy semejantes a las localizadas en conjuntos (Gonçalves, 1989: 337). Este hecho aproxima los depósitos de algunas cámaras de corredor corto con los de los monumentos más avanzados, como por otra parte confirman los pulimentados agrupados en el corredor de la Miera, del mismo modo que los de Trincones 1 (Bueno et alii 1999c) y que incluyen cinceles y azuelas, tipologías en general adscritas a momentos del neolítico final y calcolítico.

Nuestros trabajos en el término de Alcántara confirman la variabilidad arquitectónica que venimos señalando y la asociación de estas pequeñas sepulturas a cámaras de mayor tamaño, ya sean de corredor corto o de corredor largo, además de su conexión con materiales habitacionales de claro cariz calcolítico (Bueno et alii 1998a y b 1999c), que encajan con la ya mencionada fecha del dolmen de Trincones 1.

La asociación de cámaras pequeñas y sepulcros de falsa cúpula detectada al Norte de la provincia se repite al Sur en las necrópolis de Garrovillas y Sierra de San Pedro, con algún ejemplo intermedio en Brozas (Bueno et alii 2000). A ellas deberíamos añadir las noticias de monumentos de pequeño tamaño en las cercanías del poblado de los Barruecos que están por confirmar (Bueno 2000: 54). Al igual que en el Norte, poblados amurallados ocupan las proximidades de estas necrópolis (González 1993), proponiendo una evidencia más para contribuir a su adscripción cultural.

Finalmente, los datos en el cuadrante suroccidental de la provincia son más difusos (Bueno 2000: 55), pero estelas antropomorfas como la de Torrejón el Rubio (Bueno y González 1995) o Salvatierra de Santiago (González y Alvarado 1986), dan pie para proponer su asociación a necrópolis calcolíticas como las que nos ocupan (Bueno y Balbín 2000c).

ISSN: 1133-4525 ISSN-e: 2255-3924 


\section{LAS NECRÓPOLIS CON MONUMENTOS DE PEQUEÑO TAMAÑO EN LA SECUENCIA MEGALÍTICA DE LA CUENCA INTERIOR DEL TAJO.}

La consideración del papel de estas agrupaciones funerarias ha estado marcada por la propuesta del origen del megalitismo en formas arquitectónicas simples y de pequeño tamaño que habrían evolucionado hacia arquitecturas más complejas en las fases álgidas del desarrollo de este sistema de enterramiento (Arnaud 1978; Soares y Silva 2000). Este punto de partida ha ocultado una realidad arqueológica cada vez más abrumadora en la que estas pequeñas cámaras forman parte de necrópolis amplias cuya variabilidad arquitectónica y cuyos ajuares, a veces con metal (Bueno 1994), apuntan a soluciones avanzadas idénticas a las comprobadas en otras áreas del megalitismo peninsular. Tanto al Norte como al Sur, las necrópolis con monumentos de poca altura se insertan en el panorama de las necrópolis asociadas a poblados más estables que se fechan desde el Calcolítico al Bronce, con un origen probable en el Neolítico Final y un claro entronque con las costumbres y formas funerarias del megalitismo clásico.

La crítica a esa situación en el Suroeste surgió tempranamente. Ya los Leisner (1951;1967) expusieron sus dudas acerca de este esquema, dudas recogidas por otros autores que en época reciente han tenido oportunidad de releer el conjunto megalítico de Reguengos de Monsaraz (Gonçalvez y Sousa 2000: 72). Idéntica situación se refleja en los argumentos disponibles entre el Tajo y el Duero (Kalb 1987) que, en nuestro caso, conectan con la situación descrita para los conjuntos documentados al Norte del Tajo.

En 1988 afirmábamos las fechas avanzadas de algunas de estas cámaras y en 1994 proponíamos serias dudas respecto a una secuencia lineal entre sepulturas simples y complejas pues muchas de las sepulturas simples reflejaban claras contemporaneidades con las complejas y, desde luego, sus materiales no avalaban su construcción en la fase más antigua del megalitismo occidental (Bueno 1987; 1988; 1989 y 1994; Bueno et alii 1999c y 2000 b.

En los últimos años las posturas se han extremado entre los partidarios del surgimiento de estos monumentos de pequeño tamaño durante las fases más antiguas del megalitismo del Suroeste (Soares y Silva 2000; Cardoso et alii 2000) y los que asumen un polimorfismo contemporáneo al de la realización y uso de las grandes arquitecturas megalíticas (Bueno 1994:92; Oliveira 1997). Esta última postura, la del polimorfismo contemporáneo es entendida de modo diferente. Para Oliveira (2000a) sería la evidencia de tensiones sociales protagonizadas por grupos más pobres en recursos que ,incluso, habrían llegado a provocar la presencia fáctica de una frontera establecida mediante la erección de menhires. Para nosotros estas necrópolis se imbricarían en el panorama de las arquitecturas megalíticas avanzadas como respuesta a una adecuación al territorio ocupado en un ambiente de intensificación económica con un aumento demográfico notable (Bueno 2000: 63-67; Bueno et alii 1999b y 2000b).

El problema de una buena datación se palía con algunas referencias de interés: anta de Joaniña, Trincones 1 y los poblados de la zona de Vila Velha de Rodao/Fratel, además de con la valoración de presencias muy significativas como platos de borde almendrado, cazuelas con carena, campaniforme, industrias en pizarra y cuarcita, metalurgia de oro y cobre o la asociación de estas necrópolis con poblados abiertos y amurallados datables en Neolítico Final/Calcolítico e, incluso en la Edad del Bronce.A ello se suma la conexión arquitectónica entre las construcciones que nos ocupan y la evidencia del conocimiento de sistemas constructivos aplicados a las sepulturas de falsa cúpula o a las cistas.

La convivencia de sepulcros de falsa cúpula con las cámaras con corredor de poca altura (Bueno et alii 2000a), refleja un sistema constructivo muy similar que reitera las proporciones de los corredores, las alturas y la cantidad de ortostatos empleados en los parámetros camerales. La techumbre de falsa cúpula provoca la presencia de piezas de tamaño medio en sentido transversal a modo de 


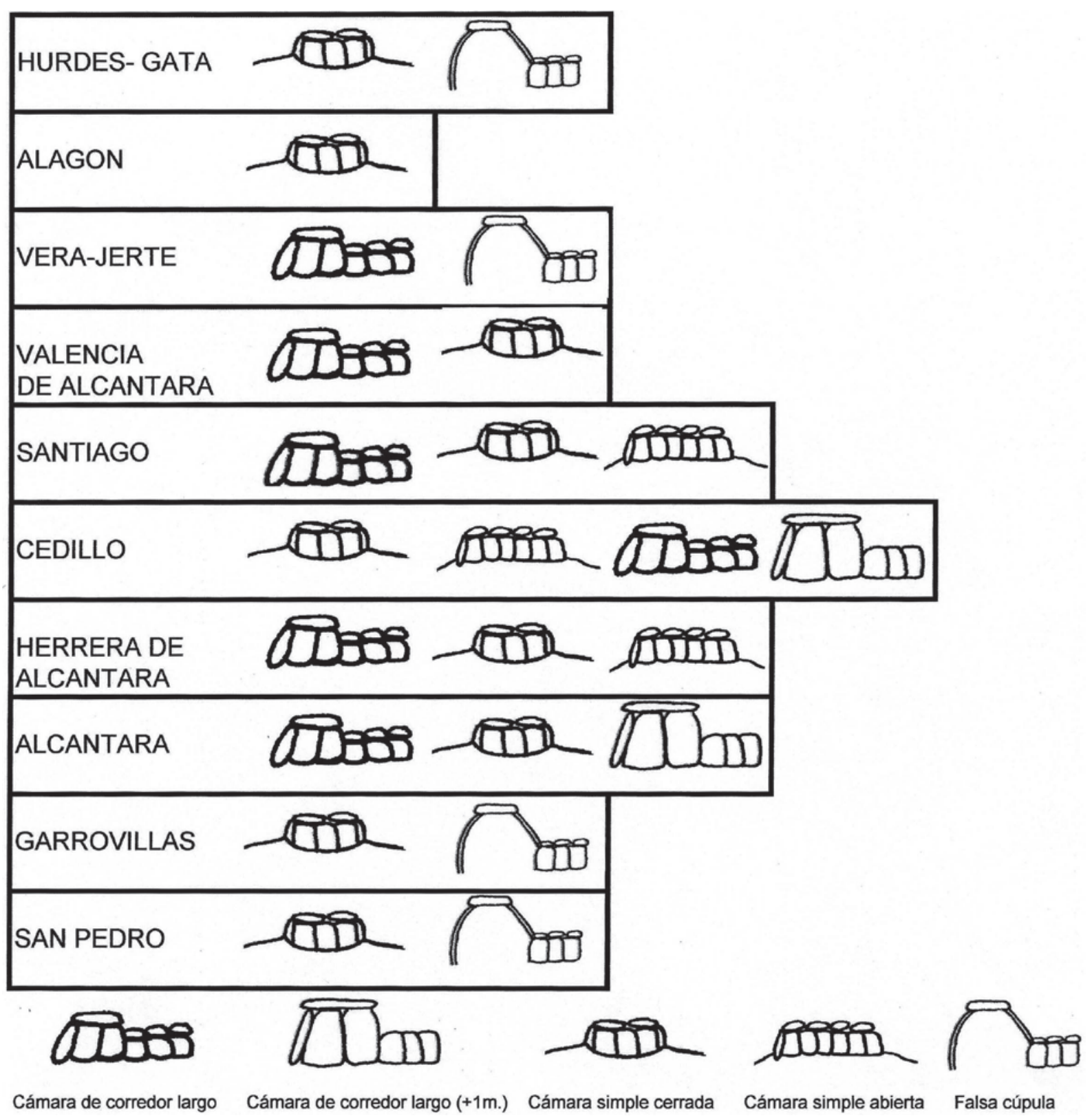

Figura 3. Asociación de arquitecturas en necrópolis con monumentos de pequeño tamaño.

paramento a seco sobre el zócalo ortostático, mientras que las techumbres planas no lo requieren. Las primeras construcciones, las de falsa cúpula, serían transitables, las segundas habrían de usarse a modo de cista, es decir levantando las cubiertas (Bueno 1994: 51-52). Cada una de las agrupaciones dentro de la necrópolis posee un sepulcro destacado, sean éstas de estructuras con falsa cúpula o pequeñas arquitecturas ortostáticas (Bueno et alii 2000a) (Figura 3).

La proximidad de las cámaras simples rectangulares cerradas al concepto de cista se verifica no sólo en la definición de ese único espacio accesible desde la zona superior, sino en la excavación de estas sepulturas en el terreno. Este procedimiento es notorio en otro tipo de cámaras de pequeño 
tamaño como la cámara rectangular abierta de Baldío Gitano I o las cámaras con corredor de Maimón 2 y Trincones 1. Esta última muestra ,además, un sistema de relleno del suelo idéntico al documentado en muchas cistas del Bronce: una capa muy compacta de piedra pequeña, barro y restos de materia orgánica, prácticamente cementicia (Enríquez y Carrasco 1995; Tavares y Soares 1981).

Los materiales documentados en los ajuares de nuestras pequeñas sepulturas repiten el contenido básico de las arquitecturas megalíticas tradicionales: armas, adornos, útiles de trabajo y contenedores, además de piezas antropomorfas (Bueno 2000), sin que ninguna parte de él haya sido excluida en razón a la supuesta pobreza de estas sepulturas.

Así los pulimentados de variada tipología de Valencia de Alcántara (Bueno 1988: 28) y Santiago de Alcántara (Bueno 1994) aparecen en casi todos los ajuares.Como muestra reciente, los localizados en Era de los Guardia y Joaniña (Oliveira 1998). Estos conjuntos de pulimentados poseen hoy un argumento cronológico en el depósito del lateral del corredor de Trincones 1 (Bueno et alii 1999c). A las hachas y azuelas tradicionales en el mundo megalítico del V milenio cal BC se suman cinceles, gubias y azuelas estrechas propias de un horizonte más avanzado que también tenemos constatado en los sepulcros de falsa cúpula, como los muy próximos de Garrovillas (Bueno 1994: 68) o en sepulcros ortostáticos de tamaño convencional, como el ya mencionado de la Miera (Enríquez y Carrasco 2000) en Valencia de Alcántara, Juan Ron I, en Alcántara (Bueno et alii 1998 y 1998b) o el recientemente excavado de Lagunita III, en Santiago de Alcántara, con un depósito de pulimentados a la entrada del corredor.

Algunos molinos y molederas comparecen en Era de los Guardias (Oliveira 1998: 239) y Trincones 1 (Bueno et alii 1999c), al igual que en otros monumentos de semejantes características del sector portugués (Oliveira 1997b: 238) (Figura 4).

La tipología lítica presentaba hojas de sílex, además de piezas en pizarra de aspecto circular (Bueno 1999: 36 y 1988: 26) bien localizadas en los horizontes habitacionales de Neolítico Final /Calcolítico de la región (Enríquez 1991; Diéguez 1965). Tras las excavaciones de Cedillo, Alcántara y Santiago de Alcántara, podemos incluir entre el ajuar lítico abundantes puntas de flecha de variada tipología (Oliveira 1998: 235), con mayoría de bases cóncavas y aletas a veces muy desarrolladas (Bueno et alii 1999c: fig. 142) como en las próximas necrópolis portuguesas (Cardoso et alii 2000: 198; Silva 1991: fig. 9,10), que generalmente se asocian al campaniforme en todo el sector, igual que ocurre en Trincones 1. La conjunción de puntas con microlitos es visible en el ajuar de Era de los Guardias, en el de Trincones 1, en el de Maimón 2, o en el de Lagunita III, con el interés de que en ocasiones las piezas se han realizado en esquisto o en cristal de roca.

El uso de materias primas distintas del sílex, caso de la pizarra o el cristal de roca, se constata en las fases avanzadas del megalitismo occidental tanto en las grandes cámaras con corredor (Bueno 1988: 170), como en sepulcros de falsa cúpula (Lago et alii 1998: 133) y se traduce en tipologías variadas que engloban formas clásicas de puntas de flecha, microlitos, láminas y alabardas junto con útiles macrolíticos entre los que destacan los palet-disques arriba mencionados. Estas industrias están empezando a valorarse en los contextos megalíticos occidentales (Cruz et alii 2000), en relación con la problemática del Languedociense a la que no escapa su documentación en áreas de habitación (Enríquez 1991).

Las placas decoradas también forman parte de los depósitos incluidos en nuestras pequeñas sepulturas. Su cronología larga (Bueno 1992; 1994; Soares 1997: 696) enlaza con el decurso cronológico que hemos sostenido para otros tipos de figuraciones antropomorfas megalíticas (Bueno 1995; Bueno y Balbín 1994; 1996 y 1997), permitiéndonos insistir una vez más en la continuidad de los contenidos ideológicos y simbólicos de los enterramientos megalíticos.

En el caso de la zona cacereña que ahora analizamos algunas placas claramente escultóricas como las de Trincones 1 , argumentan los nexos gráficos de estas pequeñas piezas con las estelas 


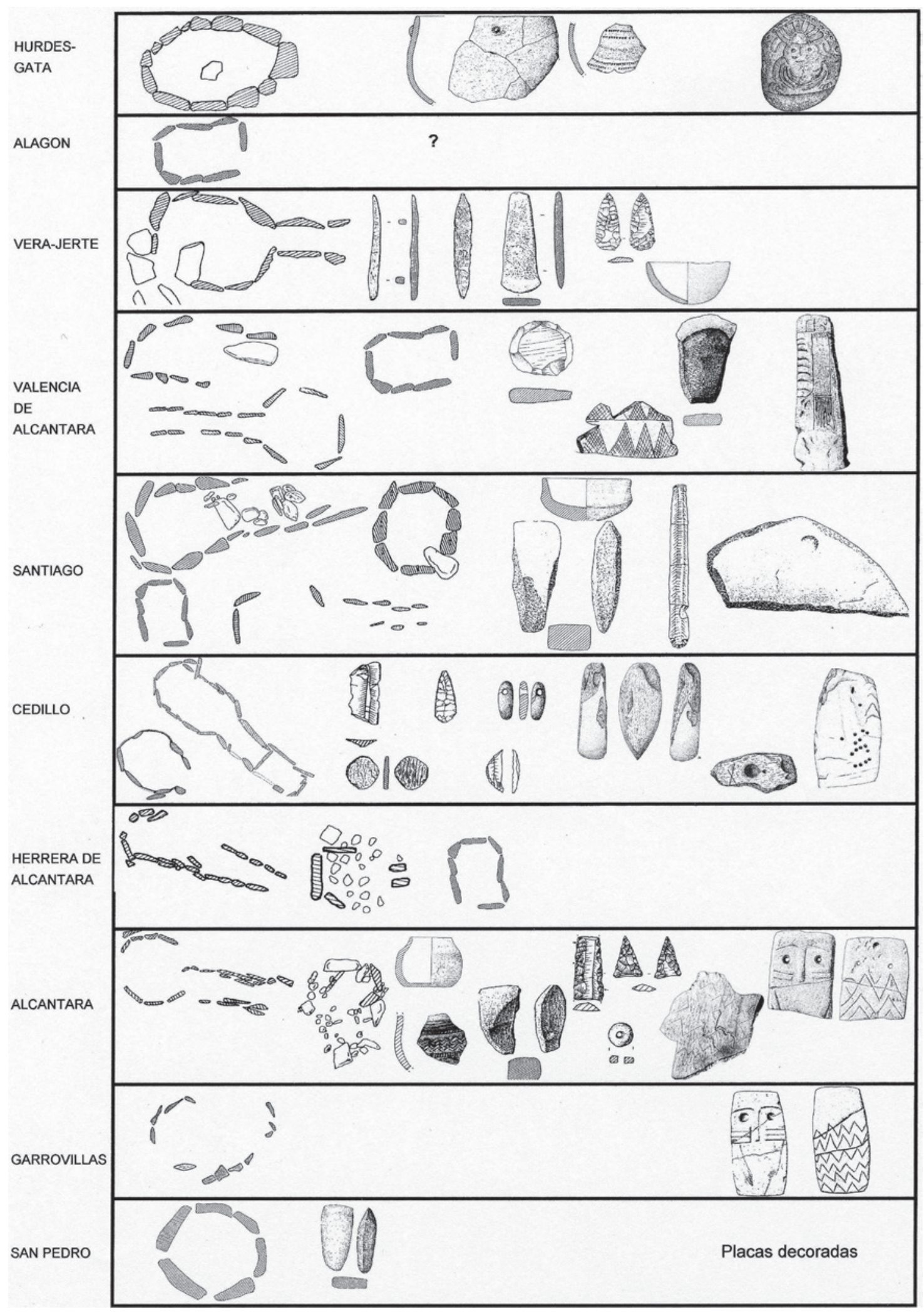

Figura 4. Arquitecturas y materiales en las necrópolis de pequeño tamaño de la provincia de Cáceres. 
antropomorfas que en su día denominamos Hurdes - Gata (Bueno 1987; 1990; 1991 y 1995). Por no alargar demasiado este aspecto que ya hemos valorado en más de una ocasión, baste recordar la pieza con manos procedente de la cámara de Trincones 1 y compararla con grafías semejantes en Granja de Toniñuelo, Ciudad Rodrigo 1 y 2, Hernán Pérez I, IV y V, Cambroncino, Arrocerezo etc. La asociación de la mencionada pieza de Trincones 1 con campaniforme inciso propone una cronología de mitad del III milenio cal BC para la realización de parte de este conjunto antropomorfo que además posee argumentos arqueológicos (Bueno y González 1995), para rastrearse cuando menos desde el Neolítico Final. (Figuras 5,6,7 y 8).

La abundante presencia de cerámica en estas sepulturas de pequeño tamaño es un hecho en las excavaciones de Alcántara y de Santiago de Alcántara. Su tipología engloba formas simples de cuencos pequeños y medianos, que son las más comunes (Bueno 1994; Oliviera 1998). Suelen tener superficies alisadas e incluso, aguadas a la almagra. Los materiales de Trincones 1 aportan una novedad en ese aspecto: pintura roja tanto al interior como al exterior, dispuesta en forma de triángulos rellenos. A estos cuencos se suman platos de borde almendrado o engrosado y cazuelas con carena baja. Entre estas últimas destaca la presencia de alguna carena muy baja y abierta, al estilo de las más clásicas del horizonte Atalaia como las documentadas por Hurtado (2000: 283) entre el material del sepulcro circular de Guadajira o, las que recientemente ha dado a conocer Oliveira (2000b: 214) procedentes del Anta 2 de S.Gens.Están asociadas a vasos con hiladas de mamelones verticales (Oliveira 2000: 206) reproduciendo el ambiente tipológico de algunas de las necrópolis más clásicas del Bronce del Suroeste como la de Quiteria, en las que también concurren cuencos pequeños y medios, además de bordes engrosados (Tavares y Soares 1981).

En el aspecto de la cerámica destaca la presencia de campaniforme que, si bien se podía sospechar a partir de la documentación de materiales como brazales de arquero o vasos lisos (Cardoso et alii 1997: fig. 13-2; 2000: 198), queda confirmada en los hallazgos de Trincones 1. Ya disponíamos en Alcántara de un conjunto liso asociado a una plaquita aúrea en el corredor del dolmen de Juan Rón 1 (Bueno et alii 1998 a y 1998b; Bueno et alii 2000b), una cámara con corredor en pizarra de buen tamaño. La concurrencia de este conjunto campaniforme en Juan Rón 1 junto con un importante depósito de pulimentados, al igual que en Trincones 1, acerca claramente ambos sepulcros desde el punto de vista cronológico constituyendo un argumento más para la valoración de la asociación en estas necrópolis de cámaras con corredor de buen tamaño junto con formas pequeñas de variada tipología (Bueno 1994: 87-88).

La documentación de campaniforme liso e inciso en la franja de la Raya incide en supuestas ausencias (Boaventura 2000: 296) explicables en la escasa investigación que ha recibido el sector. No hay que olvidar la mención a su presencia en el poblado de los Barruecos, muy próximo a Alcántara (Sauceda 1991) o en el también cercano hábitat de Monte do Trigo, en Vila Velha de Rodao (Vilaça y Cristovao 1995).

El campaniforme en la cuenca interior del Tajo reflejaría, como en el Noroeste (Jorge 1986) un elementos aditivo, incorporado como item de prestigio, asociado a la utilización de las antiguas sepulturas y a la nueva construcción de necrópolis con monumentos de pequeño tamaño, así como a la presencia de habitats en sus inmediaciones (Fábregas 2001: 96).

El campaniforme inciso localizado en el depósito inicial de la cámara de Trincones posee otro referente asociado, un brazal de arquero realizado en esquisto. Estas piezas fueron clasificadas como afiladores de objetos de metal por los hermanos Siret (1890), propuesta que hoy parece refrendada por sus huellas de uso (Castro et alii 1999: 123). Sea como fuere, las formas más alargadas entre las que encajan las piezas de Trincones 1 y la del Anta 2 de Couto da Espanhola son las mejor documentadas en contextos argáricos proponiendo para estos depósitos una cronología dentro de la segunda mitad del III milenio cal BC., que posee buen refrendo en las fechas de 

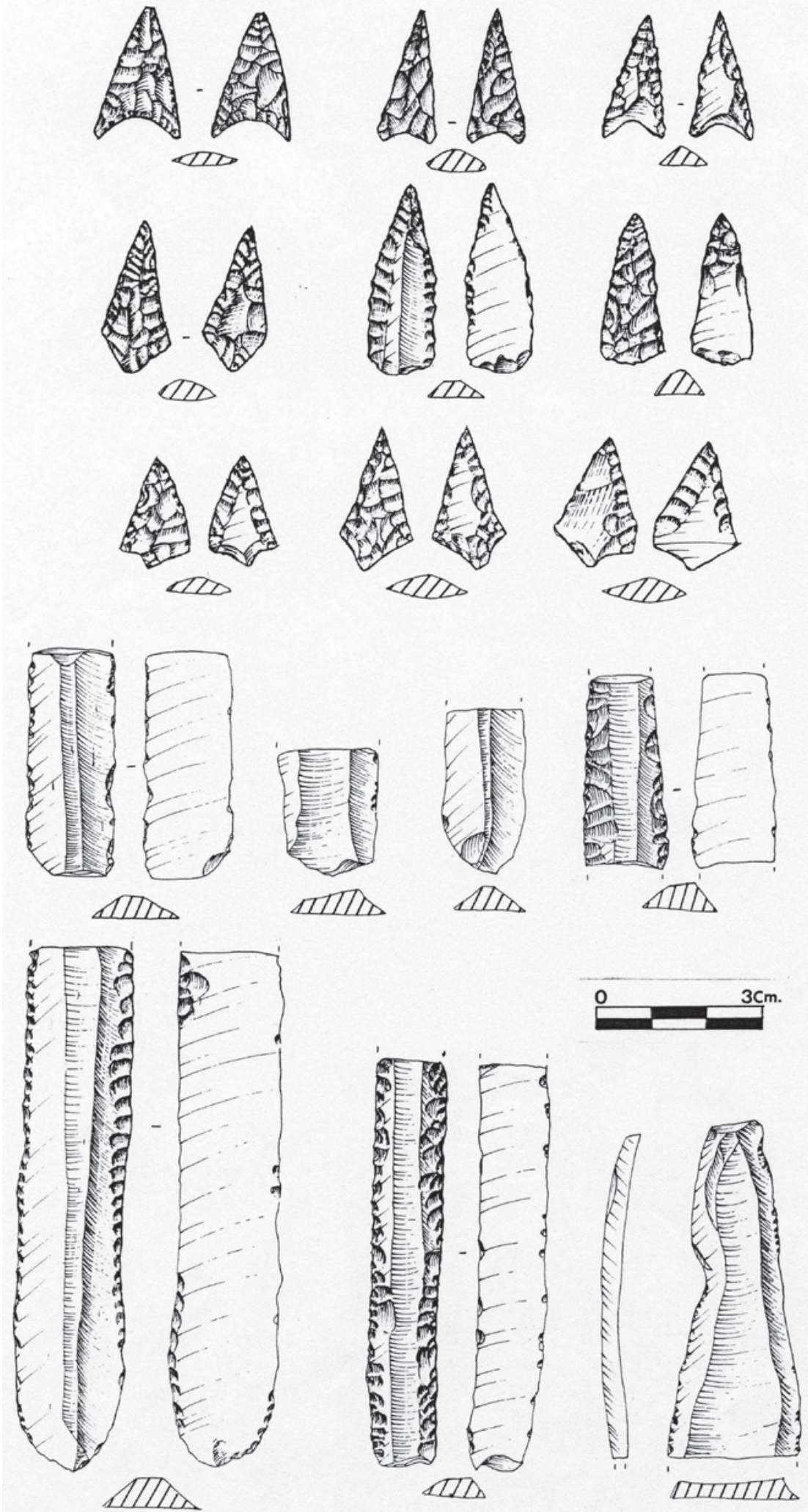

Figura 5. Material lítico del sepulcro de Trincones 1. 

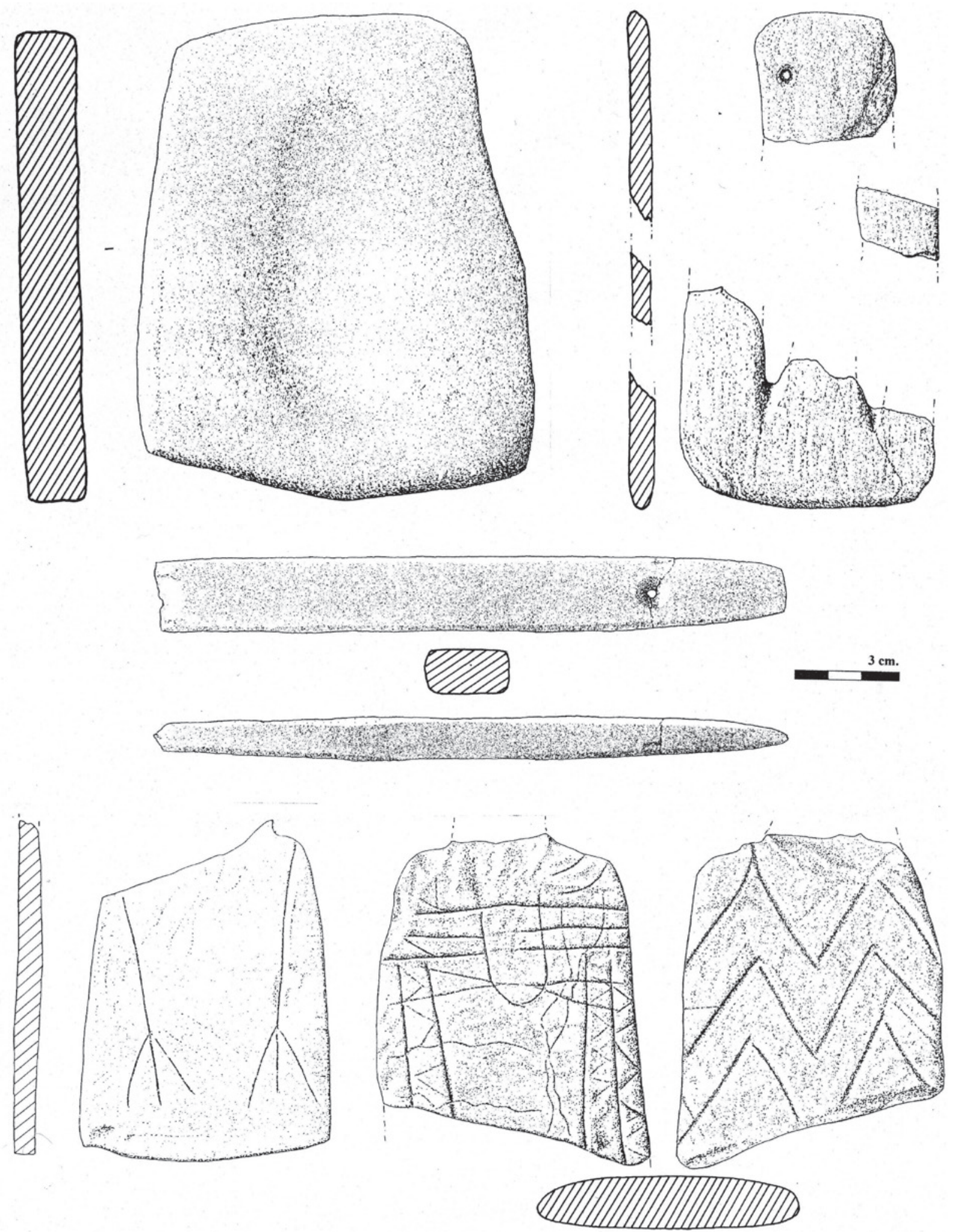

Figura 6. Placas antropomorfas y brazal de arquero del sepulcro de Trincones 1. 

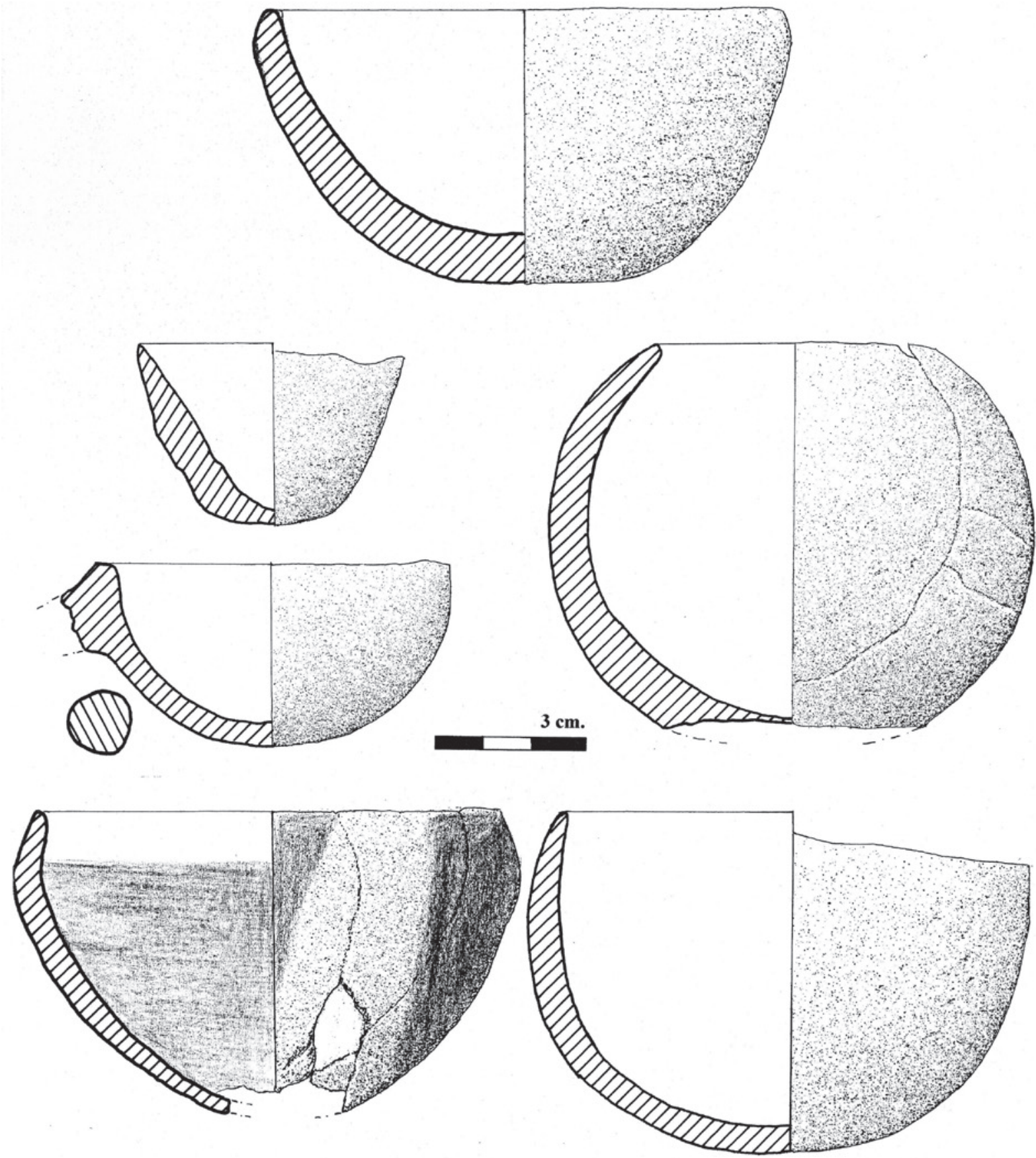

Figura 7. Material cerámico del sepulcro de Trincones 1.

Joaniña y Trincones 1 . Su contemporaneidad con el uso de cistas en el Suroeste queda demostrada en los ajuares de algunas de las arquitecturas de la necrópolis de Palmeira, como Palmeira 7 de la que procede un brazal de arquero, además de un conjunto de pulimentados que incluyen gubias y cinceles como en otros sepulcros próximos:Palmeira 6 o Palmeira 14 (Formosinho et alii 1953; Bueno 1994: 82-83). 

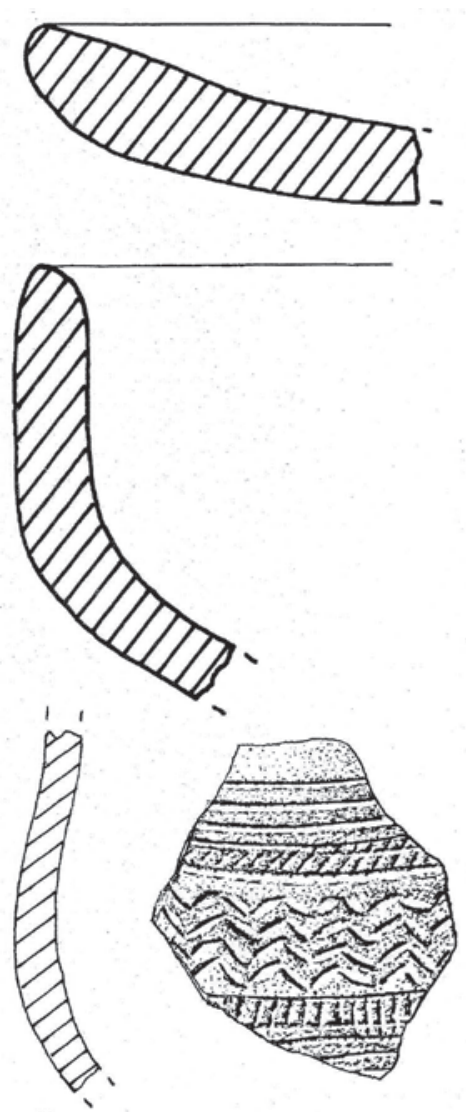
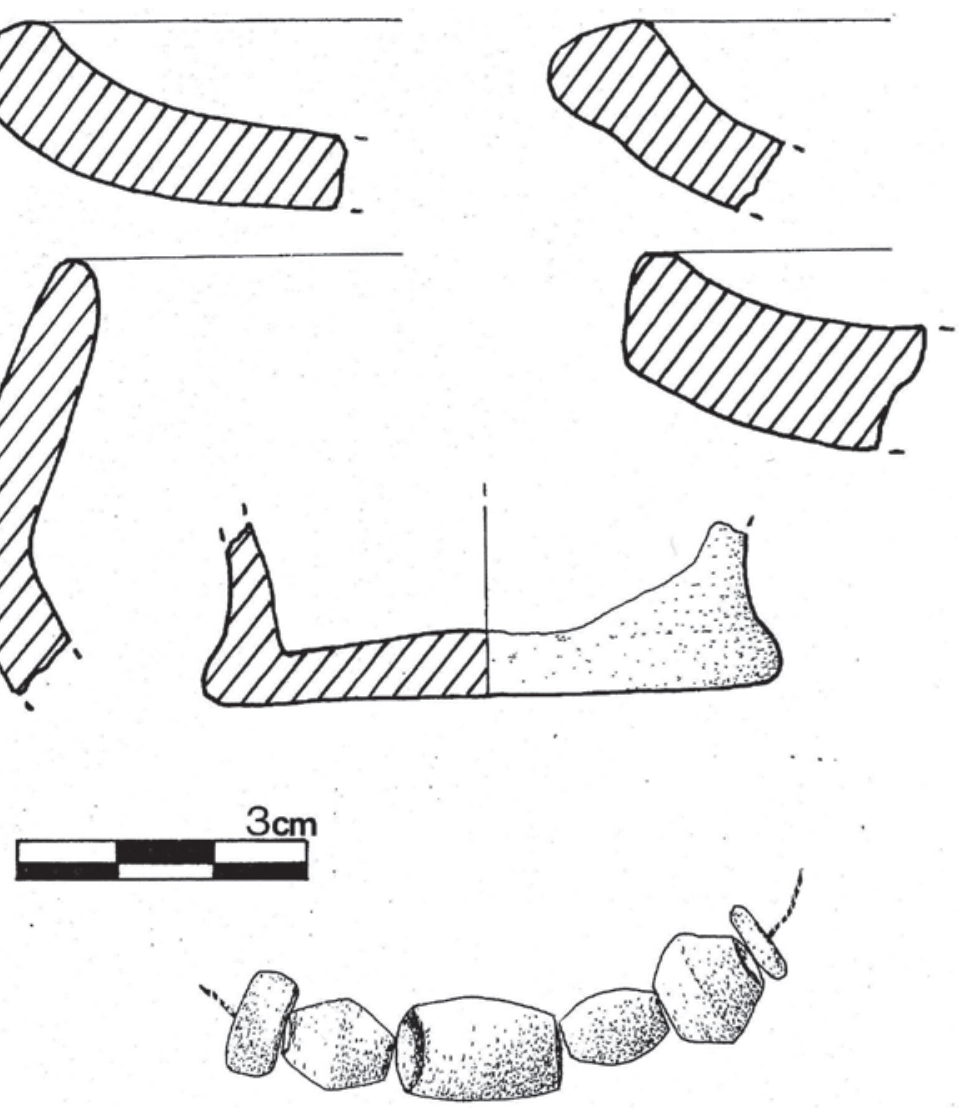

Figura 8. Platos, campaniforme inciso y elementos de adorno del sepulcro de Trincones 1.

Pequeñas cámaras con o sin corredor y cistas han convivido también con sepulturas de falsa cúpula como demuestran las fechas de la segunda fase de Huerta Montero (Blasco y Ortíz 1991) y con el uso de cuevas artificiales en el interior, como indican las muestras de C-14 sobre materiales óseos de la necrópolis del Valle de las Higueras, en Toledo (Bueno et alii 2000d). Así las primeras centurias de la Edad del Bronce se revisten en el Suroeste y el interior de una importante tradición megalítica que da lugar a que todo tipo de sepulturas estén en uso o reutilizadas, como ya hemos comentado para las arquitecturas ortostáticas con corredor corto o con corredor más desarrollado.

La asociación poblado/necrópolis es un hecho desde los primeros monumentos megalíticos (Bueno et alii,2002; Gonçalves y Sousa 2000) y tiene buenas referencias en el Neolítico Final /Calcolítico en los conjuntos mejor estudiados como Reguengos de Monsaraz. Así el poblado abierto de Areias 15 (Gonçalves y Sousa 2000: 59) con platos de borde almendrado y "tazas" de carena baja, asociado a la necrópolis das Areias formada por cartorce monumentos muy próximos entre sí. Se trata de seis cámaras con corredor, una de ellas de un metro de altura (Anta 7 das Areias) y una cista, el Anta 10, de aspecto muy similar a la de Valle Pepino I. Una referencia datada que los autores proponen para la interpretación de este poblado es la de Monte Novo dos Albardeiros, cuya fase más antigua se fecha en $4060 \pm 80$ BP y la más reciente en $3760 \pm 100$ B.P.

El panorama, bien documentado en las necrópolis de Reguengos, es trasponible al que hemos ido desgranando hasta aquí. Los sepulcros del Chanquero y el Matón en el ámbito del hábitat calcolítico detectado por González Cordero (1993). Los de las Hurdes de Madroñal junto a los poblados con materiales calcolíticos del mismo nombre, o los de la Coronita y el Collao (Bueno 
y González Cordero 1995:104). Los de Garrovillas, también cámaras con falsa cúpula y cámaras simples junto al poblado fortificado del Castillón (Sauceda 1991: 29) o, los del Canchal, reiterando la misma asociación (Bueno et alii 2000a). En la zona portuguesa próxima ya hemos hablado del poblado de Charneca do Fratel asociado a las mámoas de Charneca das Canas y podemos recordar idéntica asociación entre el poblado calcolítico fortificado de Monte da Ponte (Kalb y Hock 1997) y los monumentos que le rodean, trece, de variadas tipologías. Destacan las arquitecturas de pequeño tamaño entre las que se encuentra la cista de Albardeiros 1 (Kalb y Hock 1997: 417).

Un elemento más que nos parece muy interesante valorar en el ambiente genéricamente calcolítico que puede argumentarse para estas pequeñas necrópolis, es la presencia de materiales exóticos y de items de prestigio como evidencia de su imbricación en las redes de intercambio propias de las culturas del momento, cuestión que tiene bastante sentido, de considerar su situación en la cuenca del Tajo.

La variscita detectada por M. Edo en la composición de la multitud de cuentas que forman parte del ajuar de Trincones 1, se suma a la ya mencionada en otras cámaras del mismo estilo (Bueno 1994: Bueno et alii 2000a; Oliveira 1997b: 238), sin olvidar la presencia de campaniforme o de metal.

En este tema de los items de prestigio hay otro aspecto a destacar. Su presencia en determinadas arquitecturas de una misma necrópolis y su ausencia en otras, coincidiendo con la menor envergadura volumétrica de estas últimas y su menor despliegue de recursos gráficos (Bueno et alii 1999a 2000a; Bueno y Balbín 2000a y c). Así las necrópolis de pequeño tamaño repiten los esquemas de jerarquización detectables en arquitecturas de mayor envergadura y proponen interpretaciones más complejas que la pobreza de las arquitecturas como única explicación para la organización interna de estas agrupaciones funerarias.

Las necrópolis con monumentos de pequeño tamaño se insertan en un territorio codificado (Bueno y Balbín 2000 a y c) que mantiene las referencias simbólicas neolíticas, por tanto, las referencias ancestrales que también alimentaron la construcción de los grandes sepulcros. Probablemente una reorientación en las actividades de subsistencia acorde con una intensificación económica y un palpable aumento demográfico provocó, como en otros sectores de la Península, un aprovechamiento más eficaz del territorio. Ello se suma a una cierta democratización de las sepulturas megalíticas en la que éstas pasan a formar parte del sistema más común de enterramiento acumulándose en necrópolis organizadas, adosadas a poblados que, en ocasiones, están fortificados. Esta "democratización" (Tarrús 1987) la asumimos en el sentido de extensión y uso más generalizado del sistema, lo que no excluye la apreciación de diferencias cada vez más marcadas en la acumulación de objetos de prestigio.

Las necrópolis de pequeño tamaño como evidencia de emulación de las arquitecturas y símbolos de los ancestros, reflejan la justificación de la "tradición" (Godelier 1985 y 1987) como argumento para la afirmación y traspaso de la propiedad. El uso de los símbolos -arquitectura y grafías-, reviste a los detentadores del poder económico y social de poder ideológico con lo que obtienen una plusvalía para argumentar su control sobre la tierra, el ganado y el metal. La asociación de sepulturas más ricas y más pobres (Bueno 2000) ratificaría una organización social jerarquizada.

El proceso de asentamiento poblacional y de extensión de las fórmulas megalíticas en sepulcros más estandarizados se verifica al igual que en toda la fachada atlántica peninsular en tiempos solapados, de modo que se continúan usando sepulcros de origen más antiguo con explotaciones del territorio de aspecto más tradicional, a la par que se perciben asentamientos más amplios con necrópolis de este cariz en las que además de pequeñas arquitecturas pueden incluirse sepulturas de falsa cúpula o sepulcros ortostáticos de más de $1 \mathrm{~m}$. de altura, especialmente cámaras con corredor muy desarrollado.

ISSN: 1133-4525 ISSN-e: 2255-3924

SPAL 13 (2004)

http://dx.doi.org/10.12795/spal.2004.113.03 
El papel del campaniforme en este proceso no es tan drástico como muchas hipótesis han pretendido destacar.Continúan construyéndose enterramientos colectivos,además de reutilizándose,por lo que no es observable una dicotomia absoluta entre lo colectivo y lo individual,sino una asunción progresiva por parte de organizaciones familiares del rol atribuido a los ancestros.El aspecto simbólico reitera nuestra propuesta,mostrando una sintomática continuidad que,en todo caso,tiende a la visualización de contenidos antropomorfos cada vez más individualizados.

A los recursos tradicionales de una ganadería extensiva que en el caso del Calcolítico y Bronce en Cáceres, está documentada aunque los datos sean parcos, se suma un paisaje de dehesa con parcelas aclaradas en las que se ha sembrado cereal. Si a ello añadimos los recursos metalíferos que hemos señalado, los territorios que hemos descrito en la cuenca media del Tajo como los principales receptores de las necrópolis que nos ocupan, quedan muy alejados de la imagen de pobreza y marginalidad. Al contrario, aparecen como perfectamente imbricados en el panorama de intensificación económica asociado a los poblados estables desde el Neolítico Final en adelante, tanto al Este como al Oeste de la Península.

\section{BIBLIOGRAFIA}

ALMAGRO BASCH, M. (1962): Megalitos en Extremadura I y II. Excavaciones arqueológicas en España, 3 y 4. Ministerio de Cultura. Madrid.

- (1966): Las estelas decoradas del Suroeste. Bibliotheca Praehistórica Hispana VIII.

ALMAGRO GORBEA, M. (1977): El Bronce Final y el periodo orientalizante en Extremadura. Bibliotheca Praehistórica Hispana XIV.

ALMAGRO GORBEA, M. y HERNÁNDEZ, F. (1977): “ La necrópolis de Hernán Pérez (Cáceres)". Estudios dedicados a Carlos Callejo Serrano: 1-13.

ARNAUD, J.M. (1978): "Megalitismo em Portugal: problemas e perspectivas". Actas das III Jornadas Arqueológicas vol.I: 89-102.

BADAL, E. (1990): Aportaciones de la antracología al estudio del paisaje vegetal y su evolución en el cuaternario reciente en la costa mediterránea del País Valenciano y Andalucía (18.000-3.000 BP). Tesis doctoral microfilmada. Universidad de Valencia.

BALBÍN BEHRMANN, R.de. y BUENO RAMIREZ, P. (1989): "Arte megalítico en el Suroeste: el grabado del dolmen de Huerta de las Monjas (Valencia de Alcántara)". XIX Congreso Nacional de Arqueología, II: 237-247.

BALCELLS, E.(1979): "Aspectosecológicos generales yestadoactualdel conocimiento delos recursos". Estudio integrado y multidisciplinario de la dehesa salmantina 1, 3 fascículos. Salamanca-Jaca.

BLASCO, F. y ORTIZ, M. (1991): “Trabajos arqueológicas en Huerta Montero, Almendralejo, Badajoz." I Jornadas de Prehistoria y Arqueología en Extremadura. Extremadura Arqueológica II: $129-137$.

BRADLEY, R. (1991): Ritual, time and history. World Archaeology 23/2: 209-219.

BUENO, P. (1984): "Estatuas-menhir y estelas antropomorfas en Extremadura”. Revista de Estudios Extremeños

_ (1987): "Megalitismo en Extremadura. Estado de la cuestión”. El Megalitismo en la Península Ibérica. Ministerio de Cultura:73-84.

- (1988): Los dólmenes de Valencia de Alcántara. Excavaciones arqueológicas en España 155. Ministerio de Cultura. Madrid.

(1989): "Cámaras simples en Extremadura”. XIX Congreso Nacional de Arqueología: 385-397. 
- (1990): "Statues, menhirs et stèles anthropomorphes dans la Péninsule Ibérique". L'Anthropologie 94 (1): 85-110.

- (1991): Megalitos en la Meseta Sur: los dólmenes de Azután y La Estrella (Toledo). Excavaciones arqueológicas en España 159. Ministerio de Cultura. Madrid.

(1992): "Les plaques décorées alentajaines: approche de leur étude et analyse". L' Anthropologie 96,2-3: 499-572.

(1994): "La necrópolis de Santiago de Alcántara (Cáceres). Una hipótesis de interpretación para los sepulcros de pequeño tamaño del megalitismo occidental". Boletín del Seminario de Estudios de Arte y Arqueología LX: 25-100.

(1995): "Megalitismo, estatuas y estelas en España". Notizie Archeologiche Bergomensi 3:77-129.

(2000): "El espacio de la muerte en los grupos neolíticos y calcolíticos de la Extremadura española”. El Megalitismo en Extremadura (Homenaje a Elías Diéguez Luengo). Extremadura Arqueológica VIII: 35-80.

BUENO, P. y BALBÍN, R. (1991): "El proyecto arqueológico Valencia de Alcántara: el Jardinero y yacimientos megalíticos de la comarca de Alcántara (Cáceres)". Extremadura Arqueológica II: $89-101$.

(1991b): "La estela del Millarón y su relación con las representaciones antropomorfas megalíticas". XX Congreso Nacional de Arqueología: 199-205.

(1994): "Estatuas-menhir y estelas antropomorfas en megalitos ibéricos. Una hipótesis de interpretación del espacio funerario". Homenaje al prof. Echegaray. Museo y Centro de Altamira. Monografías 17: 337-347.

(1996): "El papel del antropomorfo en el arte megalítico ibérico". Révue Archéologique del'Ouest 8: 97-102.

(1997): "Arte megalítico en sepulcros de falsa cúpula. A propósito del monumento de Granja de Toniñuelo (Badajoz)." III Congreso Internacional de Arte megalítico. Brigantium 10: 91-121.

(1997b): Ambiente funerario en la sociedad megalítico ibérica: arte megalítico peninsular". En A. Rodríguez Casal (Ed): O Neolítico atlántico e as orixes do megalitismo: 693-718.

(1998): "Novedades en la estatuaria antropomorfa megalítica española". Actes du 2ème colloque international sur la statuaire mègalithique. Archèologie en Languedoc 22: 43-60

(2000a): "La grafía megalítica como factor para la definición del territorio". Arkeos 10: 129-178.

(2000b): "Art mégalithique et art en plein air. Approche de la définition du térritoire pour les groupes producteurs de la Péninsule Ibérique". L' Anthropologie 104 (3): 427-458.

- (2000c):"Arte megalítico en Extremadura". El Megalitismo en Extremadura (Homenaje a Elías Diéguez Luengo ). Extremadura Arqueológica VIII:345-379

BUENO, P.; BALBÍN, R. y BARROSO, R. (2000d): Valle de las Higuera (Huecas, Toledo, España). Una necrópolis Ciempozuelos con cuevas artificiales al interior de la Península. Estudos Préhistóricos 8: 49-80.

BUENO, P.; BALBÍN, R. y BARROSO, R. (2005): El dolmen de Azután: áreas de habitación y áreas funerarias en el interior de la Península. Diputación Provincial de Toledo.Universidad de Alcalá de Henares.

BUENO, P.; BALBÍN, R.; BARROSO, R.; ALCOLEA, J.; VILLA, R. y MORALEDA, A. (1999b): Poblamiento megalítico en las riberas del Guadyerbas: El dolmen de Navalcán (Toledo). Servicio de Arqueología de la Diputación de Toledo.

BUENO, P.; BALBÍN, R.; BARROSO, R.; ALDECOA, A. y CASADO, A. (1998): “Dolmenes en la cuenca del Tajo: restauración y consolidación de megalitos en Alcántara (Cáceres). Trabajos de Prehistoria 55 (1): 171-183.

ISSN: 1133-4525 ISSN-e: 2255-3924

SPAL 13 (2004)

http://dx.doi.org/10.12795/spal.2004.113.03 
(1998b): Sepulcros megalíticos en el Tajo: Excavación y Restauración de dólmenes en Alcántara, Cáceres, España”. Ibn Maruán 8: 135-182.

(2000b): "Dólmenes en Alcántara (Cáceres). Un proyecto de consolidación e información arqueológica en las comarcas extremeñas del Tajo. Balance de las campañas de 1997 y 1998 ". El Megalitismo en Extremadura (Homenaje a Elías Diéguez Luengo). Extremadura Arqueológica VIII: $129-169$.

BUENO, P.; BALBÍN, R.; BARROSO, R.; CASADO, A. y ALDECOA, A. (1999c): "Proyecto de excavación y restauración en dólmenes de Alcántara (Cáceres). Segunda Campaña”. Trabajos de Prehistoria 56 (1): 131-146.

BUENO, P.; BALBÍN, R.; BARROSO, R.; ROJAS, J.M.; VILLA, R.; FÉLIX, R. y ROVIRA, S. (1999a): "Neolítico y Calcolítico en Huecas (Toledo): el túmulo de Castillejo. Campaña de 1998". Trabajos de Prehistoria 56.2:141-160.

BUENO, P. y CORDERO, A. (1995): "Nuevos datos para la contextualización arqueológica de estatuas - menhir y estelas antropomorfas en Extremadura". $1^{\circ}$ Congresso de Arqueología Peninsular. Trabalhos de Antropología e Etnología 35 (1):95-110.

BUENO, P.; CORDERO, A. y ROVIRA, S. (2000a): "Areas de habitación y sepulturas de falsa cúpula en la cuenca extremeña del Tajo. Acerca del poblado con necrópolis del Canchal en Jaraíz de la Vera (Cáceres)". El Megalitismo en Extremadura (Homenaje a Elías Diéguez Luengo). Extremadura Arqueológica VIII:211-244.

BUENO, P.; JIMÉNEZ, P. y BARROSO, R. (1995): "Prehistoria reciente en el Noreste de Guadalajara”. En R. de Balbín, J. Valiente y M. Mussat (coord): Arqueología en Guadalajara:73-95.

(2002): "Culturas productoras, culturas metalúrgicas y grafías en la provincia de Guadalajara. Estado de la cuestión”. Primer Simposio de Arqueología en Guadalajara:

BUENO, P. y PIÑÓN, F. (1985): "Los grabados del sepulcro megalítico de Magacela (Badajoz)". Series de arqueología extremeña 1: 65-81.

BUXÓ I CAPDEVILA, R. (1999): "Carpología y valoración agrícola”. En M.D. Camalich Massieu y D. Martín Socas: El territorio almeriense desde los inicios de la producción hasta fines de la antigüedad. Un modelo: la depresión de Vera y cuenca del río Almanzora. Arqueología. Monografías: 289-305.

CARDOSO, J.L.; CANINAS, J.C. y HENRIQUES, F. (1997): “ A anta 2 de Couto da Espanhola. (Rosmaninhal. Idanha-a-Nova)". Estudios Pré-históricos. 5: 9-28.

(2000): "Arquitectura, espolio e rituais de dois monumentos megalíticos da Beira Interior: estudo comparado". Trabalhos de Arqueología 16: 195-214.

CARRASCO, M.J. y ENRÍQUEZ, J.J. (2000): "El sepulcro metalítico de Las Arquetas (Fregenal de la Sierra, Badajoz)". El Megalitismo en Extremadura (Homenaje a Elías Diéguez Luengo). Extremadura Arqueológica VIII:325-342.

CARROBLES, J;; MUÑOZ, K. y RODRÍGUEZ, S. (1994). "Poblamiento durante la Edad del bronce en la cuenca media del Tajo". La Edad del Bronce en Castilla - La Mancha: 173-200.

CASTAÑOS, P. (1991): "Animales domésticos y salvajes en Extremadura. Origen y evolución". Revista de Estudios extremeños XLVII: 9-67.

— (1992): "Estudio arqueozoológico de la fauna del Cerro de la Horca (Plasenzuela, Cáceres)." Archaeofauna 1: 127-146.

CASTRO, V.; CHAPMAN, R.; GILI I SURIÑACH, S.; LULL, V.; MICO, R.; RIHUETE, C.; RISCH, R. y SANAHUJA, E. (1999): Proyecto Gatas 2. Arqueología. Monografías. Junta de Andalucía.

CELESTINO PÉREZ, E. (2001): Estelas de guerrero y estelas diademadas. La precolonización y formación del mundo tartésico. Bellaterra arqueología. Barcelona. 
CERRILlO, E. (1999): "La cueva de El Conejar (Cáceres). Avance al estudio de las primeras sociedades productores en la Penillanura cacereña". Zephyrvs LII:107-128.

CRUZ, A.; GRIMALDI, S.; OOSTERBEEK, L. y ROSINA, P. (2000): "Industrias macrolíticas do Pos-glaciar no alto Ribatejo". Neolitização e Megalitismo da Península Ibérica. ADECAP: 47-60.

DALLMEYER, R.D. y GARCÍA, M.E. (1990): Pre-Mesozoic Geology of Iberia. Berlin.

DELIBES, G. y SANTONJA, M. (1986): El fenómeno megalítico en la provincia de Salmanca. Diputación provincial de Salamanca.

DIEGUEZ LUENGO, E. (1965): "Nuevas aportaciones a la prehistoria de Extremadura". Zephyrus XVI: 129-130.

(1976): "Los dólmenes de Valencia de Alcántara". V Congreso de Estudios extremeños: 25-42.

DUQUE ESPINO, D. (2005): "Aproximación al paisaje vegetal de los grupos megalíticos del sever a partir de los datos antracológicos de varios dólmenes". En P. ARIAS; R. ONTAÑÓN y C. GARCÍA-MONCÓ (eds.): III Congreso del Neolítico en la Península Ibérica: 125-134.

ENRÍQUEZ NAVASCUES, J.J. (1988): "Informe sobre las excavaciones llevadas a cabo en el yacimiento de Araya (Mérida, Badajoz) 1983 y 1984". Extremadura arqueológica I: 11-19. (1991): El Calcolítico o Edad del Cobre de la cuenca extremeña del Guadiana: los poblados. Museo de Badajoz. Publicaciones 2. Badajoz.

ENRÍQUEZ NAVASCUES, J.J. y CARRASCO, M.J. (1995): "La necrópolis de cistas de Las Arquetas (Fregenal de la Sierra, Badajoz) y otros restos de necrópolis de cistas en las estribaciones occidentales de la Sierra Morena extremeña". Spal 4: 101-130.

ENRÍQUEZ NAVASCUES, J.J. y HURTADO, V. (1986): "Prehistoria y Protohistoria", Historia de la Baja Extremadura t.I. Badajoz: 3-85.

FABIAN, J. (1995): El aspecto funerario durante el Calcolítico y los inicios de la Edad del Bronce en la Meseta Norte. Universidad de Salamanca.

FÁBREGAS, R. (2001): Los petroglifos y su contexto: un ejemplo de la Galicia meridional. Instituto de Estudios vigueses.

FLORIDO LARAÑA, P. (1987): La minería en Extremadura. Junta de Extremadura. Mérida.

FORMOSINHO, J.; FERREIRA. O. y VIANA, A. (1953): "Estudos arqueológicos nas Caldas de Monchique", Trabalhos de Antropología e Etnología, XIV: 66-224.

GARCÍA FIGUEROLA, M. (1985): Guía arqueológica de la Sierra de Gata. Cáceres.

GIL-MASCARELL, M.; RODRÍGUEZ, A. y ENRÍQUEZ, J.J. (1986): "Enterramientos en cistas de la Edad del Bronce en la Baja Extremadura". Saguntum 20: 9-41.

GODELIER, M. (1985): Economía, fetichismo y religión en la sociedades primitivas. Siglo XXI. Madrid

(1989): Lo ideal y lo material. Pensamiento, economía, sociedades. Taurus. Madrid.

GOMES, M.V. (1997): "Anta da Belhoa (Reguengos de Monsaraz. Evora). Resultado da campanha de escavações de 1992". Cuadernos de Cultura de Reguengos de Monsaraz 1: 39-69.

GONÇALVES, V.S. (1989): "A ocupaçao pré-histórica de Monte Novo dos Albardeiros (Reguengos de Monsaraz)". Portugalia, nova serie IX-X: 49-61.

_ (2001): "A Anta 2 da Herdade de Santa Margarida (Reguengos de Monsaraz)". Revista Portuguesa de Arqueología, 4 nº 2: 115-206.

GONÇALVES, V.S. y SOUSA, A.C. (2000): "O grupo megalítico de Reguengos de Monsaraz e a evolução do megalitismo no Occidente peninsular." Trabalhos de Arqueología 16: 11-104.

GONZÁLEZ CORDERO, A. (1993): "Evolución, yacimientos y secuencia en la edad del Cobre de la Alta Extremadura." $1^{\circ}$ Congresso de Arqueología peninsular. Actas II. Trabalhos de Antropología, Etnología y Prehistoria 33: 237-259.

ISSN: 1133-4525 ISSN-e: 2255-3924

SPAL 13 (2004)

http://dx.doi.org/10.12795/spal.2004.i13.03 
(1996): "Asentamientos neolíticos en la Alta Extremadura”. I Congrés de Neolitic a la Península Ibérica. Rubricatum 2:697-705.

(1997): "Poblamiento de la Edad del Cobre en la Alta Extremadura: sector de Valdecañas (Cáceres)." II Congreso de Arqueología Peninsular. T. II: Neolítico, Calcolítico y Bronce. Zamora: 471-482.

(1999). "Comunidades neolíticas en los riberos alto-extremeños del Tajo". II Congrés de Neolitic a la Península Ibérica. Saguntum. PLAV Extra 2: 531-540.

GONZÁLEZ CORDERO, A. y ALVARADO, M. (1986): "La estela antropomorfa de Salvatierra de Santiago (Cáceres)". Studia Zamorensia VII: 259-366.

GONZÁLEZ CORDERO, A.; ALVARADO, M.; MUNICIO, L. y PIÑÓN, F. (1988): "El poblado de El Cerro de la Horca (Plasenzuela, Cáceres). Datos para la secuencia del Neolítico Tardío y la Edad del Cobre en la Alta Extremadura". Trabajos de Prehistoria 45:87-102.

GONZÁLEZ CORDERO, A.; CASTILLO, J. y HERNÁNDEZ LÓPEZ, M. (1991): "La secuencia estratigráfica en los yacimientos calcolíticos del área de Plasenzuela (Cáceres)". Extremadura Arqueológica II: 11-26.

GONZÁLEZ CORDERO, A. y CERRILLO, E. (2000):El proceso de neolitización en la comarca extremeña de la Vera". Madrider Mitteilungen.

GUILLÉN OTERINO, A. (1982). "Sobre la introducción del castaño Castanea Sativa en el Mediterráneo Occidental". Zephyrus, XXXIV-XXXV.

HURTADO PÉREZ, V. (1995): "Interpretación sobre la dinámica cultural de la cuenca media del Guadiana (IV - II milenio a.n.e.)". Homenaje a la Dra Mila Gil - Mascarell Boscá. Extremadura Arqueológica V: 53-80.

(1999): "Los inicios de la complejización social y el campaniforme en Extremadura". Spal 8: 47-83.

(2000): "El proceso de transición a la Edad del Bronce en la Cuenca Media del Guadiana. Ruptura o continuidad". Pré-Historia Recente da Península Ibérica. ADECAP: 381-397.

HURTADO PÉREZ, V. y ENRÍQUEZ, J.J. (1991): "Excavaciones en Palacio Quemado (Alange, Badajoz). Informe preliminar". Extremadura Arqueológica II: 69-88.

HURTADO PÉREZ, V. y HUNTZ, M. (1999): "Extremadura”. En G. DELIBES e I. MONTERO (eds): Las primeras etapas metalúrgicas en la Península Ibérica. II: Estudios regionales: 241-274.

JORGE, V. (1986): "Monumentalizaçao e necropolizaçao no megalitismo europeu". Trabalhos de Antropología e Etnología XXIV, 1-4: 233-237.

KALB, P. (1987): "Monumentos megalíticos entre o Tejo e o Douro." El megalitismo en la Península Ibérica. Ministerio de Cultura. Madrid: 95-109.

KALB, P. y HOCK, M. (1997): “O povoado fortificado, calcolítico do Monte da Ponte, Evora”. II Congreso de Arqueología Peninsular. T.II: Neolítico, Calcolítico y Bronce: 417-423.

LAGO, M.; DUARTE, C.; VALERA, A.; ALBERGARIA, J. y CARVALHO, A.F. (1998): "Povoado dos Perdigoes (Reguengos de Monsaraz): dados preliminares dos trabalhos arqueológicos realizados em 1997”. Revista Portuguesa de Arqueología, 1: 45-152.

LEISNER, G. y V. (1935): "La estela-menhir de la Granja de Toniñuelo". Investigación y Progreso IX:

_ (1943): Die Megalitgräber der Iberischen Halbinsel: Der Süden. Römisch- Germanische Forschungen, 17. Berlín.

(1951): Antas do concelho de Reguengos de Monsaraz. Lisboa.

(1953). "Contribuçao para o registro das antas portuguesas. A regiao de Montargil. Concelho de Ponte do Sor". O Archeologo Portugues. Lisboa 2. Serie 2: 227-256.

(1959): Die Megalithgräber der Iberischen Halbinsel. Der Westen. Berlín. (1967): Die verschiedenen phasen des neolithikuns in Portugal. Paleohistoria, 12

LEISNER, V. y SCHUBART, H. (1964): "Dólmenes de Ciudad Rodrigo". Zephyrus XV: 47 y ss. 
LÓPEZ, P. (1994): "Análisis polínicos". Apéndice a P. Bueno : "La necrópolis de Santiago de Alcántara (Cáceres). Una hipótesis de interpretación para los sepulcros de pequeño tamaño del megalitismo occidental”. Boletín del Seminario de Estudios de Arte y Arqueología LX:97-100.

LÓPEZ PLAZA, S.; FRANCISCO, J.L. y SALVADOR MATEOS, R. (2000): "Megalitismo y vías naturales de comunicación en el SO salmantino". Neolitização e Megalitismo da Península Ibérica. ADECAP:271-288.

MALUQUER, J. (1956): Carta arqueológica de España. Salamanca. Servicio de Investigaciones arqueológicas. Diputación provincial de Salamanca.

MARISCAL, B.(1996): "Evolución de la vegetación desde el Calcolítico a la primera Edad del Hierro en la cuenca media del Tajo". Estudios Palinológicos: 83-86.

MARTÍN ARROYO, T.; RUIZ ZAPATA, B.; VALDEOLMILLOS, A. y BENITO, D. de (1996): "Reconstrucción de la vegetación durante el cuaternario reciente en el Puente del Arzobispo (Toledo. España): primeros datos polínicos". Estudios Palinológicos: 91-94.

MÉLIDA, J.R. (1924): Catálogo monumental de España. Provincia de Cáceres (1914-16). Madrid.

NOCETE, F. (2001): Tercer milenio antes de nuestra era. Relaciones y contradicciones centrolperiferia en el Valle del Guadalquivir. Bellaterra. Barcelona.

OLIVEIRA, J. (1997): Sepulturas megalíticas del término municipal de Cedillo. Provincia de Cáceres. Ayuntamiento de Cedillo.

_ (1997b): "Datas absolutas de monumentos da Bacia hidrográfica do río Sever". II Congreso de Arqueología Peninsular. T. II: Neolítico, Calcolítico y Bronce: 229-239.

(1998): "A anta da Joaninha e a da Era de los Guardias (Cedillo. Cáceres) no ambiente megalítico da foz de Sever". Ibn Maruan 8: 203-245.

— (2000a): "Economía e sociedade dos construtores do megalitos da bacia do Sever. Neolitização e Megalitismo da Península Ibérica. ADECAP:429-445.

_ (2000b): "A anta II de San Gens (Nisa)". Ibn Maruan 9/10: 181-238.

OSUNA RUIZ, M. (1975): "El dolmen del Portillo de las Cortes (Aguilar de Anguita, Guadalajara”. Noticiario Arqueológico Hispánico 3: 237-309.

PARREIRA, R. y SERPA, F (1995): "Novos dados sobre o povoamento da regiao de Alcalar (Portimao) no IV e III milenios A.C." $1^{\circ}$ Congresso de Arqueología Peninsular. Trabalhos de Antropología e Etnología 35 (3):233-256.

PAVÓN SOLDEVILA, I. (1998): El cerro del Castillo de Alange (Badajoz). Intervenciones arqueológicas 1.

(1998b): El tránsito del II al I milenio en las cuencas medias de los ríos Tajo y Guadiana: la Edad del Bronce. UNEX. 328p.

PERPETUO, J.; SANTOS, F.; CARVALHO, P.S.; GOMES, L.F. y SERRA, A.A. (1999). Tabuaço. Un passado presente. Catálogo.

RAMOS, J. y GILES, F. (1996): "El dolmen de Alberite (Villamartín)". Universidad de Cadiz y Ayuntamiento de Villamartín.

REDONDO GONZÁLEZ, A. y DEL RÍO LAFUENTE, I. (1977): Cáceres en Los Paisajes naturales de Segovia, Avila, Toledo, Cáceres. Estudio geográfico. Dir. E. Martínez Pisón: 177-248.

ROSO DE LUNA (1901): "Ruinas prehistóricas de Logrosán, Santa Cruz de la Sierra y Solana de las Cabañas". Revista Extremeña III,24: 249-256.

SANCHES, M.de J. (2000): "Reflexoes sobre o povoamento do Neolítico inicial do Norte de Portugal (VI-IV mil. A.C.)." Neolitização e megalitismo da Península Ibérica. ADECAP: 181-203.

SANTOS, A.T. (2000): "O megalitismo da área da barragem Marechal Carmona (Concelho de Idanha -a- Nova). Uma análise espacial." Neolitização e megalitismo da Península Ibérica. ADECAP: 413-428.

ISSN: 1133-4525 ISSN-e: 2255-3924

SPAL 13 (2004)

http://dx.doi.org/10.12795/spal.2004.i13.03 
SAUCEDA, M.I. (1991): "La secuencia cultural de Los Barruecos. Malpartida de Cáceres (Cáceres). " Extremadura arqueológica II:27-44.

SCHUBART, H. (1973): "Tholos- Bauten von Colada de Monte Nuevo bei Olivenza". Madrider Mitteilungen 14: 11-32.

(1975): "Tumbas megalíticas con enterramientos secundarios de la Edad del Bronce de Colada de Monte Nuevo de Olivenza”. XII Congreso Nacional de Arqueología: 175-189.

SEVILLANO SAN JOSÉ, M.C. (1982): "Un nuevo hallazgo en Extremadura: el ídolo-estela de El Cerezal". Zephyrus XXXIV-XXXV: 165-171.

SILVA, F.A.P. da (1991): Mamoa da Charneca das Canas. Fratel. Concelho de Vila Velha de Rodao. Cámara Municipal de Vila Velha de Rodao.

SIRET, H. y SIRET, L. (1890): Las primeras edades del metal en el sudeste de España. 2 vol.

SOARES, A.M. (1997): “ Megalitismo e cronología absoluta”. II Congreso de Arqueología Peninsular. T. III: Primer Milenio y metodología: 689-706.

SOARES, A.M.M. y CABRAL, J.M.P. (1987): "O povoado fortificado calcolítico do Monte da Tumba VI. Cronología absoluta”. Setubal Arqueológica VIII: 155-165. (1993): "Cronología absoluta para o Calcolítico da Estremadura e do Sul de Portugal". I Congresso de Arqueología Peninsular. Actas II. Trabalhos de Antropología e Etnología 32 (3-4): 217-235.

SOARES, J y SILVA, C.T. (2000): "Protomegalitismo no Sul de Portugal: inauguração das paisagens megalíticas". Trabalhos de Arqueología 16: 117-134.

SORIA SÁNCHEZ, V. (1979): "Hallazgos arqueológicos recientes en Extremadura". Revista de Estudios Extremeños, t. XXXV, II: 353-361.

SOUSA, O. (1996): Estatuaria antropomorfica pré e proto- histórica do Norte de Portugal. Dissertação para a obtenção do Mestrado em Arqueología. Porto.

SOUSA, O. y REBANDA, N. (1993): "As estelas-menires do Cabeço da Mina. Vila - Flor. Trasos-Montes. Portugal. Resúmenes. IIIrd Deia International Conferences of Prehistory: 27-28.

TARRUS I GALTER, J. (1987): "El megalitisme de l' Alt Empordá (Giroa). Els constructors de dòlmens entre el Neolitic Mitjà i el Calcolitic à l' Albera, Serrra de Roda i Cap de Creus". Cota Zero. 3: 35-54.

TAVARES, C. y SOARES, J. (1981): Pré- historia da area da Sines. Gabinete de area da Sines. Lisboa.

VALERA, A.C. (2000): "A problemática da neolitização dos territórios do interior: o caso da bacia do alto e medio Mondego". Por terras de Viriato. Arqueología da região de Viseu. Viseu: 15-22.

VERNET, J.L.; BADAL, E. y GRAU ALMERO, E. (1983): "La végétation néolithique du sud-est de l'Espagne (Valencia, Alicante) d’après l'antrhacologie". C. R. Académie des Sciences, 296. III: 669-672.

(1975): Die Kultur der Bronzezeit im Südwesten der Iberische Halbinsel. Berlin.

VILAÇA, R. (1995): Aspectos do povoamento da Beira interior (centro e sul) nos finais da idade do Bronze. Trabalhos de Arqueología 9. IPPAR. 2 vol.

(2000): "Registros e leituras da pré-história recente e da proto-história antiga da Beira interior". Pré-histórica recente da península Ibérica. ADECAP:161-182.

VILAÇA, R. y CRISTOVAO, E. (1995): "Povoado pré-histórico de Monte do Trigo (Idanha-aNova)". Estudos Pré-históricos 3: 201-211. 